Bundesgesundheitsbl 2015 $\cdot 58: 308-322$

DOI 10.1007/s00103-014-2114-1

Online publiziert: 10. Februar 2015

(c) Springer-Verlag Berlin Heidelberg 2015
Martina Kraus-Haas ${ }^{1} \cdot$ Martin Mielke $^{1} \cdot$ Arne Simon $^{2}$

${ }^{1}$ Robert Koch-Institut Berlin, Berlin, Deutschland

2 Pädiatrische Onkologie und Hämatologie, Universitätsklinikum des Saarlandes, Homburg/Saar, Deutschland

\title{
Literatur-Update zu Ausbrüchen auf neonatologischen Intensivpflegestatio- nen - Serratia marcescens, Klebsiella pneumoniae, Acinetobacter baumannii und Pseudomonas aeruginosa
}

\section{Hintergrund}

Häufungen von Infektionen mit einem (vermeintlich) einheitlichen Erreger in neonatologischen Intensivpflegestationen (NICUs) sind unerwünschte Ereignisse, durch die die Sicherheit der Patienten und ein günstiger Ausgang der Intensivtherapie gefährdet wird [1]. Mitunter sterben die Kinder an unmittelbaren Komplikationen bzw. langfristigen Folgen dieser „Late-onset“-Infektionen oder ihre psychomotorischen und mentalen Entwicklungsoptionen werden durch diese Ereignisse nachhaltig beeinträchtigt [2] Ausbrüche bedingen zudem erhebliche Mehrbelastungen des Behandlungsteams (zu dem wir auch das Hygienefachpersonal zählen) [3] und können zur vorübergehenden oder dauerhaften Schließung einer Abteilung führen [4-8]. Aufgrund der besonderen Infektionsgefährdung der Patienten, der strukturell-organisatorischen Besonderheiten der Intensivtherapie in NICUs, des initial sehr uncharakteristischen klinischen Bildes und aufgrund des speziellen Erregerspektrums (z. B. Serratia marcescens) müssen Ausbrüche auf NICUs separat von anderen Ausbrüchen betrachtet werden [1].

Die Kommission für Krankenhaushygiene und Infektionsprävention (KRINKO) beim Robert Koch-Institut in Ber- lin hat 2007 spezielle Empfehlungen zur Prävention von nosokomialen Infektionen bei intensivmedizinisch behandelten Frühgeborenen mit einem Geburtsgewicht unter $1500 \mathrm{~g}$ publiziert [9] und diese in den Jahren 2012 [10] und 2013 [11] aktualisiert. Dabei wurde erstmals 2012 ein Kolonisationsscreening empfohlen, das neben individualmedizinischen Zielsetzungen dazu dienen soll, frühzeitig die nosokomiale Übertragung von Infektionserregern zu erkennen $[12,13]$. Schon der Nachweis einer vermehrten nosokomialen Übertragung soll eine Intensivierung der Basishygiene, z. B. durch zusätzliche Maßnahmen der Barrierepflege, der Isolierung und/oder Kohortierung nach sich ziehen. Auf diese Weise sollen der Kolonisation nachfolgende nosokomiale Infektionen und insbesondere auch Infektionsausbrüche nach Möglichkeit verhindert werden [14].

Im Hintergrund der ergänzenden KRINKO-Empfehlungen wurde von einer interdisziplinären Arbeitsgruppe die Risikocharakterisierung für diese $\mathrm{Pa}$ tientengruppe aktualisiert [13]. Im Rahmen dieses Vorhabens erfolgte unter anderem eine systematische Literaturrecherche, die an die von Gastmeier et al. 2007 vorgelegte Analyse [1] der Besonderheiten von Infektionsausbrüchen in NICUs anknüpfte (siehe Infobox).
Ziel der hier vorgestellten Übersicht ist es, die Ausbruchssituation, die Methoden zur Untersuchung sowie die Maßnahmen zur Kontrolle des Ausbruchs bei Ausbrüchen in NICUs durch bestimmte, häufig vorkommende gramnegative Erreger (Klebsiella pneumoniae, Serratia marcescens, Acinetobacter baumannii, Pseudomonas aeruginosa) detaillierter zu beschreiben. Zu Ausbrüchen durch Staphylococcus aureus gibt es einen eigenen Beitrag (ebenfalls in dieser Zeitschrift). Ausbrüche durch Enterobacter cloacae wurden nicht berücksichtigt, weil dies den Rahmen der Publikation deutlich überschritten hätte. E. cloacae $[15,16]$ wurden in NICUs vor allem als kolonisierende (seltener als Infektionen verursachende) Bakterienspezies beschrieben [13]. Gramnegative Erreger mit speziellen Resistenzen und Multiresistenzen [17] werden in dieser Analyse nach der Systematik der KRINKO-Empfehlungen als 3MRGN und als 4MRGN [18] oder als 2MRGN NeoPäd [11] ausgewiesen. Bei letzteren handelt es sich um gramnegative Erreger, die in vitro gegen Piperacillin und Cephalosporine der Gruppe III und/oder IV resistent, jedoch gegen Carbapeneme und Fluorchinolone sensibel sind. 


\begin{abstract}
Infobox P. Gastmeier: Outbreaks in neonatal intensive care units
In einem systematischen Review untersuchten Gastmeier et al. [1] Unterschiede zwischen in der medizinischen Fachliteratur publizierten nosokomialen Infektionsausbrüchen in neonatologischen Intensivpflegestationen (NICUs) und Intensivstationen anderer Fachgebiete (andere ICUs, auch für Erwachsene). Dazu führten sie am 25. Juli 2005 eine Suche in der Outbreak Database (http://www.outbreak-database.com) durch. Die Outbreak Database enthält systematisch aufbereitete Informationen aus im Volltext zugänglichen Publikationen über nosokomiale Ausbrüche und wurde zur Unterstützung des Ausbruchsmanagements in medizinischen Einrichtungen etabliert [35]. Letztendlich wurden 276 Ausbrüche in NICUs mit 453 Ausbrüchen in anderen ICUs verglichen. Demnach stammten 38 \% aller Berichte aus ICUs, gespeichert in der Outbreak Database zum Zeitpunkt der Abfrage, aus NICUs. Die wichtigsten Zielparameter waren dabei die Spezies des Infektionserregers (Ausbruchsisolat), Art der Infektion, gemeinsame Infektionsquelle (falls nachgewiesen), Maßnahmen zur Unterbrechung der Ausbrüche, Nachweis des Ausbruchsisolates beim Personal und Mortalität ${ }^{1}$.

Die bei Ausbrüchen in NICUs am häufigsten isolierten Infektionserreger waren Klebsiella spp. [ $n=56\left(20 \%{ }^{2}\right)$, davon 14 ESBL-Bildner], gefolgt von Staphylococcus spp. [ $n=44(16 \%)$, davon $n=27$ MRSA] und Serratia spp. [ $n=33(12 \%)$ ]. Enterobacteriaceae als Gruppe (Klebsiella spp., Serratia spp., Enterobacter spp., Escherichia spp., Salmonella spp., Citrobacter spp.) verursachten insgesamt $53 \%$ der hier analysierten Ausbrüche in NICUs; hingegen wurden Enterobacteriaceae bei anderen ICUs nur in $20 \%$ aller Ausbrüche gefunden, häufigste Erreger in anderen ICUs waren Staphylokokken [ $n=91$ (20\%), davon 72 MRSA]. Zwischen Ausbrüchen in NICUs und solchen in anderen ICUs gab es signifikante Unterschiede in Bezug auf die Art der nosokomialen Infektionen. Aus NICUs wurde am häufigsten über Blutstrominfektionen (Sepsis) berichtet (NICUs $63 \%$ vs. andere ICUs $47 \% ; p<0,001$ ), gefolgt von gastrointestinalen Infektionen (NICUs $21 \%$ vs. andere ICUs $10 \% ; p<0,001$ ), ZNS-Infektionen (NICUs $20 \%$ vs. andere ICUs $4 \% ; p<0,001$ ), Pneumonien (NICUs $19 \%$ vs. andere ICUs $32 \% ; p<0,001$ ) und „HNO Infektionen plus Konjunktivitis“ (NICUs $15 \%$ vs. andere ICUs $2 \% ; p<0,001$ ). Ausbrüche von postoperativen Wundinfektionen machten nur $4 \%$ aller Berichte von NICUs vs. $22 \%$ der Berichte von anderen ICUs aus $(p<0,001)$.

Im Mittel wurde das Ausbruchsisolat in den NICUs pro Ausbruch bei 23,9 Patienten nachgewiesen (von im Mittel 13,7 bei Acinetobacter spp. bis 37,3 bei S. aureus). Die berichtete Mortalität variierte je nach Infektionserreger und lag im Durchschnitt bei 6,4 \%. Eine Mortalität über $10 \%$ wurde bei Infektionen durch Klebsiella spp. (12 \%), Pseudomonas spp. (11 \%), Salmonella spp.(13\%) und Candida spp. (11 \%) beobachtet. Nur $26 \%$ der NICU-Ausbrüche (ebenso nur $26 \%$ aller Berichte aus anderen ICUs) wurden in systematisch in einer Fall-Kontroll- oder Kohortenstudie aufgearbeitet [67]. Bei $62 \%$ der Ausbrüche in NICUs und bei 68 \% der analysierten Ausbrüche aus anderen ICUs wurden die Erreger genotypisiert. In 49 \% der Ausbrüche in den NICUs und $38 \%$ der Ausbrüche in anderen ICUs wurde keine gemeinsame Infektionsquelle identifiziert $(p=0,005)$; in den NICUs fand sich eine gemeinsame Quelle in 5,8 \% in kontaminierten Arzneimitteln oder Infusaten (vs. 1,5\%; $p=0,002$ ), bei anderen ICUs stammten die Erreger häufiger aus der Umgebung der Patienten. In $44 \%$ der NICU-Ausbrüche wurde ein Personalscreening durchgeführt. Die Zahl der pro Ausbruch positiv getesteten Mitarbeiter lag im Mittel bei 1,8 (0,2 bei Acinetobacter spp. bis 4,1 bei S. aureus). Von allen NICU-Ausbrüchen waren $11 \%$ mit einem besiedelten oder infizierten Mitarbeiter des Behandlungsteams assoziiert ${ }^{3}$ (vs. $8 \%$ bei anderen ICUs; n. s. ${ }^{4}$ ). Die Ausbruchskontrolle erfolgte in der Regel durch ein Maßnahmenbündel.

Ein Screening aller Patienten ( 66 \% vs. 48 \%), die Intensivierung der Händehygiene (53\% vs. $34 \%$ ), Isolierung oder Kohortierung der besiedelten oder infizierten Patienten (50 \% vs. $34 \%$ ) und der Einsatz patientenbezogener Schutzkittel (30\% vs. $22 \%$ ) wurden in NICUs signifikant häufiger implementiert als in anderen ICUs. Rund $16 \%$ der NICUs und $13 \%$ der anderen ICUs mussten im Verlauf des Ausbruchs vorübergehend für Aufnahmen geschlossen werden [8]. Nach Auffassung der Autoren unterliegen diese Daten einem „reporting bias", z. B. durch die vorrangige Publikation von Ausbrüchen mit großer Patientenzahl oder einem multiresistenten Erreger. Sie stellen demnach nur die „Spitze des Eisberges" dar.
\end{abstract}

\section{Methoden}

$\mathrm{Zu}$ folgenden, häufig an Ausbrüchen in NICUs beteiligten gramnegativen Erregern wurde jeweils eine systematische MEDLINE-Recherche in PubMed unter Verwendung der MeSH-Database durchgeführt: Serratia marcescens, Klebsiella pneumoniae, Acinetobacter baumannii und Pseudomonas aeruginosa. Die verwendeten Schlagworte waren: [Intensive Care, Neonatal OR Intensive Care Units, Neonatal] AND [Disease Outbreaks OR Disease Transmission, Infectious] AND [Serratia marcescens] bzw. jeweils einer der oben genannten Erreger. Die Suche wurde eingeschränkt auf Publikationen

\footnotetext{
1 Anteil der in zeitlichem Kontext des Ausbruchs verstorbenen Kinder, kausaler Zusammenhang mit der Infektion nicht immer eindeutig.

2 Alle Prozentangaben wurden zur besseren Lesbarkeit auf- oder abgerundet.

3 Kausaler Zusammenhang nicht immer eindeutig.

4 n. S. = nicht signifikant.
}

ab 01.01.2010 bis zum 28.02.2013. Einschlusskriterien waren englisch- und deutschsprachige Veröffentlichungen aus Europa, den USA, Kanada und Australien. Eine Ausnahme stellt die Publikation von Tamma et al., Johns Hopkins Medical Institutions, Baltimore, USA [19] dar, die über einen Ausbruch in einer NICU im Nahen Osten berichten. Nach Durchsicht der Abstracts wurden zwei Reviews und ein Kurzbericht ausgeschlossen. Zur Erfassung der aktuellsten Artikel, die noch keine MeSH-Begriffe haben, wurde für 2013 ergänzend eine Suche über PubMed mit den freien Stichwörtern [Neonatal intensive care unit] AND [outbreak OR transmission] durchgeführt. Durch Freihandsuche wurde zusätzlich ein Artikel aufgenommen.

Die eingeschlossenen Publikationen wurden hinsichtlich folgender Items analysiert und die Extraktion der Informationen/Daten durch zwei unabhängige Untersucher (MKH, AS) vorgenommen: - Basisinformationen (Autor, Referenz, Land, Setting, Bettenzahl NICU, Cha- rakteristikum des Infektionserregers, Untersuchungszeitraum und Studientyp)

- Molekulargenetische Typisierung/ Methode der Typisierung

- Anzahl der Patienten mit Kolonisation und/oder Infektion

- Anteil der Patienten mit Infektion an allen Patienten mit Erregernachweis

- (Infektions- oder Manifestationsrate)

- Art der Infektion

- Letalität (bezogen auf die Infektion) ${ }^{5}$

- Screening (Maßnahmen zur Identifizierung betroffener Personenkreise; Patienten, Personal)

- Übertragungswege/Infektionsquellen in der Umgebung

- Personalmangel/Überbelegung als möglicher Risikofaktor

\footnotetext{
5 Patienten, die in zeitlichem Kontext zur Infektion verstorben sind und bei denen nach Auffassung der Autoren der entsprechenden Studie ein kausaler Zusammenhang zur Infektion bestand.
} 
- Maßnahmen zur Eindämmung des Ausbruchs (gab es dabei Besonderheiten?)

\section{Ergebnisse}

Die Recherche zu Ausbrüchen durch Serratia marcescens ergab acht Publikationen, von denen nach den genannten Kriterien fünf in die weitere Analyse eingeschlossen wurden. Hinzu kam ein Artikel [20] durch Freitextsuche in PubMed. Für Klebsiella pneumoniae ergaben sich 11 Treffer, von denen vier Publikationen für die weitere Analyse ausgewählt wurden. Die Freitextsuche in PubMed ergab auch hier eine weitere Arbeit [21]. Die gezielte Recherche zu Ausbrüchen durch Acinetobacter baumannii ergab zwei Artikel, die beide in die Analyse einbezogen wurden. Bei der Suchanfrage zu Ausbrüchen durch Pseudomonas aeruginosa erhielten wir vier Ergebnisse, von denen zwei Publikationen für die weitere Analyse ausgewählt wurden. Hinzu kam ein Artikel über Freihandsuche [22]. Von den insgesamt 28 identifizierten Artikeln (25 davon durch eine systematische MEDLINE-Recherche in PubMed unter Verwendung der MeSH-Database und drei durch Freitextsuche in PubMed bzw. Freihandsuche) wurden 16 nach den oben beschriebenen Auswahlkriterien in die Analyse eingeschlossen (• Abb. 1).

\section{Ausbrüche durch Serratia marcescens}

\section{Ausgangssituation}

Arslan et al. [23] berichteten in einer deskriptiven Studie über einen Ausbruch durch Serratia marcescens in einer NICU in der Türkei im Dezember 2005. Innerhalb von drei Tagen erkrankten sieben Frühgeborene, die alle eine parenterale Ernährung erhielten, an einer Sepsis. Am ersten Tag verstarb eines dieser Frühgeborenen unter prolongierter Beatmung an einer Lungenblutung.

In einer NICU in Italien evaluierten Ligozzi et al. [24] zur Untersuchung eines Ausbruchs durch S. marcescens eine PCR-Methode (rep-PCR) im Vergleich mit der PFGE (Pulsfeld-Gelelektrophorese). Von August bis Dezember 2007 wurde bei 16 Patienten eine Kolonisation

Bundesgesundheitsbl 2015 · 58:308-322 DOI 10.1007/s00103-014-2114-1

(c) Springer-Verlag Berlin Heidelberg 2015

M. Kraus-Haas · M. Mielke · A. Simon

Literatur-Update zu Ausbrüchen auf neonatologischen Intensivpflegestationen - Serratia marcescens, Klebsiella pneumoniae, Acinetobacter baumannii und Pseudomonas aeruginosa

\section{Zusammenfassung}

Gehäufte Nachweise von fakultativ pathogenen Bakterien in klinischen Materialien (abgenommen bei Infektionsverdacht) und in Abstrichen zur mikrobiologischen Surveillance müssen in neonatologischen Intensivpflegestationen (NICUs) aufgrund der besonderen Patientencharakteristika, des klinischen Bildes und des Erregerspektrums separat von Ausbrüchen in anderen Intensivstationen betrachtet werden. Zur Verbesserung des Ausbruchsmanagements und der Prävention ist es sinnvoll, die aktuelle Literatur zu Ausbrüchen in NICUs regelmäßig zu analysieren. Der hier vorgelegte Beitrag aktualisiert und er- weitert eine 2007 publizierte Übersicht von Gastmeier et al. und analysiert NICU-Ausbrüche durch Serratia marcescens, Klebsiella pneumoniae, Acinetobacter baumannii und Pseudomonas aeruginosa.

Schlüsselwörter Ausbruch · Frühgeborene . Neonatologische Intensivpflegestation . Klebsiella pneumoniae. Serratia marcescens.

Acinetobacter baumannii .

Pseudomonas aeruginosa

\section{Update on outbreaks reported from neonatal intensive care units: Serratia marcescens, Klebsiella pneumoniae, Acinetobacter baumannii, and Pseudomonas aeruginosa}

\section{Abstract}

In terms of the unique risk profile, the clinical course of nosocomial infections, and the most prevalent bacterial pathogens, literature on outbreaks of potentially pathogenic bacteria on neonatal intensive care units (NICUs) needs to be analyzed separately from reports derived from other intensive care units. With the purpose of updating important information for those involved in outbreak management and fostering preventive efforts, this article summarizes the results of a systematic literature analysis, referring to an earlier publication by Gastmeier et al. This re- view focuses on NICU outbreaks caused by Serratia marcescens, Klebsiella pneumoniae, Acinetobacter baumannii, and Pseudomonas aeruginosa.

\section{Keywords}

Outbreak . Premature infants .

Neonatal intensive care unit .

Klebsiella pneumoniae.

Serratia marcescens.

Acinetobacter baumannii .

Pseudomonas aeruginosa oder Infektion mit S. marcescens festgestellt; sechs Kinder entwickelten eine Infektion (Infektionsrate $38 \%$; Bakteriämie, Konjunktivitis, Harnwegsinfektion, Nabelinfektion). Bei einem weiteren, von Bayramoglu et al. beschriebenen Ausbruch durch $S$. marcescens in einer NICU in der Türkei wurde von März bis Mai 2006 bei neun Patienten eine Infektion diagnostiziert, ein Kind war lediglich kolonisiert. Drei von neun Kindern mit Infektion verstarben an einer Sepsis [25]. MacDonald et al. [26] untersuchten die Kolonisation von sechs und die Infektion eines beatmeten Frühgeborenen (mit Nachweis von S. marcescens im
Trachealsekret) in einer NICU in Halifax, Kanada. Der Indexpatient hatte das Isolat wahrscheinlich von seiner Mutter erworben (postoperative Wundinfektion). Die Übertragung des Ausbruchsisolates setzte sich trotz Kontaktisolierung von beatmeten Kindern auf andere Patienten fort, die im gleichen Raum betreut wurden. Polilli et al. [27] beschrieben einen Ausbruch durch ein 2MRGN NeoPäd S. marcescens-Isolat, der im April 2011 in einer NICU in Pescara, Italien beobachtet wurde. Drei Tage nach der Entlassung eines Neugeborenen, das wegen einer S. marcescens-Sepsis in die NICU verlegt und erfolgreich antibiotisch behandelt wur- 


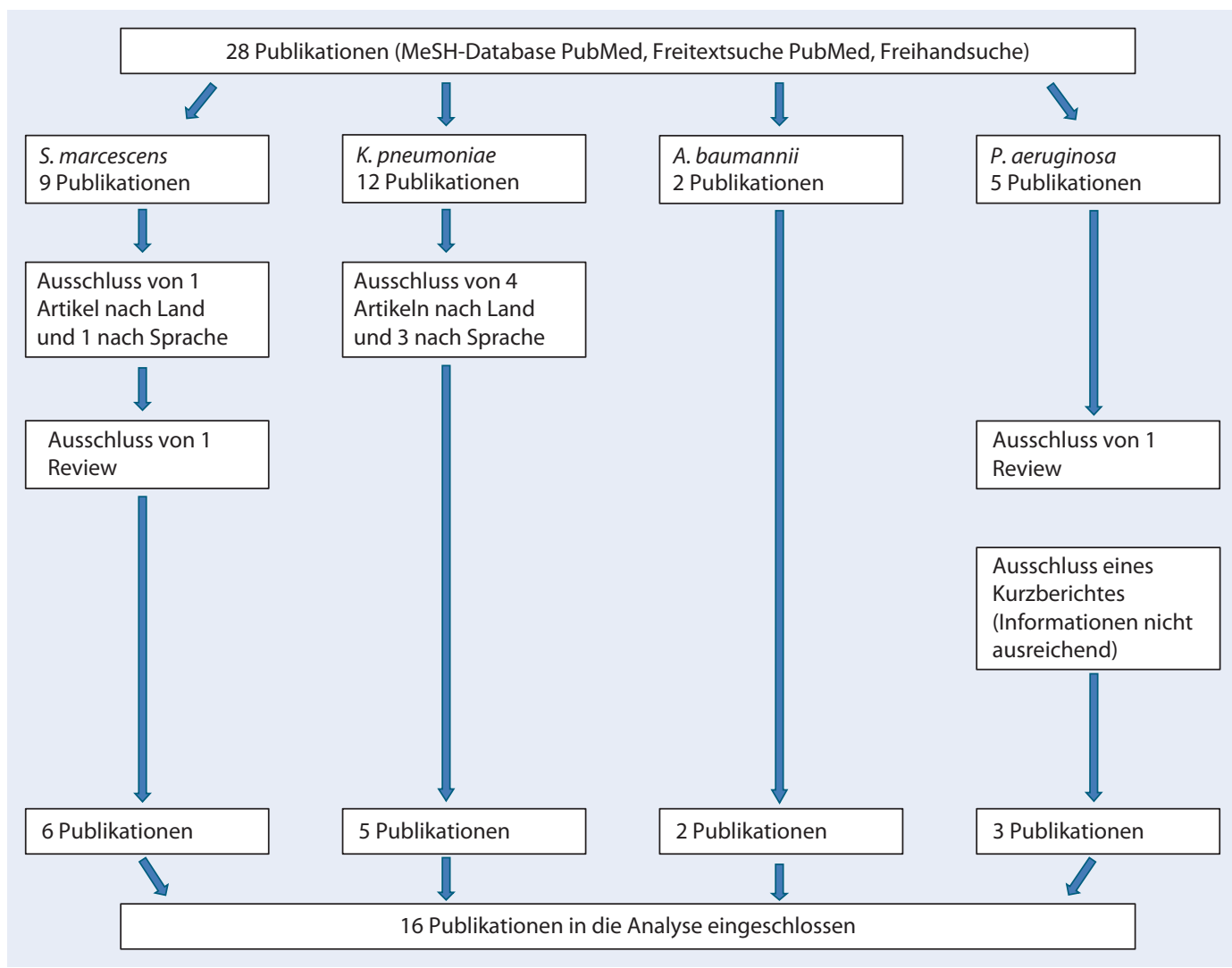

Abb. $1<$ Schematische Übersicht zur Auswahl der in die Analyse eingeschlossenen Publikationen de, entwickelten vier von 16 Patienten eine Sepsis mit Nachweis von S. marcescens. Zwei der vier Frühgeborenen verstarben wahrscheinlich infolge der Infektion. Bei einem weiteren Frühgeborenen wurde post mortem eine Kolonisation festgestellt. Maltezou et al. [20] berichteten über drei konsekutive Ausbrüche innerhalb von 35 Monaten mit S. marcescens in einer NICU in Griechenland. In diesem Krankenhaus werden pro Jahr ca. 300 Neugeborene auf die NICU aufgenommen, darunter ca. 100 mit einem Geburtsgewicht < 1500 g. Der Anteil der Patienten mit mindestens einmaligem Nachweis von S. marcescens lag bei $12 \%$ beim ersten Ausbruch, 47 \% beim zweiten Ausbruch und $42 \%$ beim dritten Ausbruch. Insgesamt wurde $S$. marcescens bei 57 Patienten nachgewiesen, von denen 37 kolonisiert waren und 20 eine Infektion entwickelten (Infektionsrate $35 \%$ ). Alle 20 Neugeborenen mit Infektion entwickelten eine „Late-onset“-Sepsis im Mittel nach 21 Lebenstagen (Range, 1-75 Tage). - Tab. 1 fasst wichtige Informationen zu diesen Ausbrüchen zusammen.

\section{Ausbruchsuntersuchung}

In der Studie von Arslan et al. [23] wurde $S$. marcescens in Blutkulturen der infizierten Kinder und in Kulturen der parenteralen Ernährungslösungen, die in Gebrauch waren, gefunden (Isolate mit gleichem genetischem Profil). Dies legt nahe, dass die nosokomiale Sepsis durch die Verabreichung kontaminierter parenteraler Ernährungslösung verursacht wurde. In der Untersuchung von Ligozzi et al. [24] wurde S. marcescens aus verschiedenen klinischen Proben, aus Muttermilchproben von fünf Ammen und aus einer Umgebungsprobe (Siphon) isoliert. Die Kulturen von den Händen des Personals zeigten kein Wachstum. Mittels der beiden o. g. Methoden (rep-PCR und PFGE) wurden 36 epidemiologisch zusammenhängende und acht nicht zusammenhängende Isolate untersucht. Die PFGE zeigte ein Hauptmuster (Typ A) und 12 genetisch nicht zusammenhängende Muster. Insgesamt 32 Isolate von 15 Patienten und von drei Ammen waren genetisch identisch und gehörten zum Muster Typ A. Die rep-PCR Analyse identifizierte drei verschiedene Muster (Typen a, b, c), die alle Typ A PFGE-Isolate einschloss sowie
12 einzelne Profile. Die Ergebnisse weitergehender Untersuchungen zeigten, dass die Typen a, und $c$ als in hohem Maße zusammenhängend klassifiziert werden sollten und bestätigten den monoklonalen Ursprung des Ausbruchs. Die Quelle des Ausbruchs war wahrscheinlich kontaminierte Spenderinnenmilch. Die Kinder von zwei der Ammen waren mit einem Isolat kolonisiert, das auch in der Muttermilch nachgewiesen wurde. Die gespendete Muttermilch wurde nicht mikrobiologisch untersucht und gepoolt.

Bei Bayramoglu et al. [25] zeigte ein Vergleich der verschiedenen Isolate von Patientenproben, Händen des Personals und Muttermilchproben mittels PFGE, dass die Isolate von zwei Kindern und von einer Handwaschprobe genetisch jeweils unterschiedlich waren. Dennoch nehmen die Autoren an, dass eine Übertragung durch vorübergehende Kontamination der Hände in dem Ausbruch eine Rolle gespielt haben könnte. Bei zwei Kindern könnte möglicherweise kontaminierte Muttermilch eine Rolle gespielt haben, wobei dies letztendlich nicht geklärt werden konnte. 


\section{Originalien und Übersichten}

\begin{tabular}{|c|c|c|c|c|c|c|}
\hline Autor & $\begin{array}{l}\text { Arslan } \\
\text { et al. [23] }\end{array}$ & $\begin{array}{l}\text { Ligozzi } \\
\text { et al. [24] }\end{array}$ & $\begin{array}{l}\text { Bayramoglu } \\
\text { et al. [25] }\end{array}$ & $\begin{array}{l}\text { MacDonald } \\
\text { et al. [26] }\end{array}$ & $\begin{array}{l}\text { Polilli } \\
\text { et al. [27] }\end{array}$ & $\begin{array}{l}\text { Maltezou } \\
\text { et al. [20] }\end{array}$ \\
\hline Land & Türkei & Italien & Türkei & Kanada & Italien & Griechenland \\
\hline Setting & NICU, Universität & NICU, Universität & $\begin{array}{l}\text { NICU, Lehrkran- } \\
\text { kenhaus }\end{array}$ & $\begin{array}{l}\text { NICU, Lehrkran- } \\
\text { kenhaus }\end{array}$ & $\begin{array}{l}\text { NICU, regionales } \\
\text { Krankenhaus }\end{array}$ & $\begin{array}{l}\text { NICU, regionales } \\
\text { Krankenhaus }\end{array}$ \\
\hline Bettenzahl NICU & 17 & $\mathrm{kA}$ & 20 & 56 & $\mathrm{kA}$ & $\begin{array}{l}\text { Insges. 57, } \\
11 \mathrm{NICU} \\
11 \mathrm{IMC} \\
35 \mathrm{SC}\end{array}$ \\
\hline MRGN? & Kein MRGN & Kein MRGN & $\mathrm{kA}$ & $\mathrm{kA}$ & 2MRGN NeoPäd & Kein MRGN \\
\hline Zeitraum & $10-12.12 .2005$ & $08 / 2007-12 / 2007$ & $03 / 2006-05 / 2006$ & Juni 2004 & April 2011 & $12 / 2007-09 / 2010$ \\
\hline Studientyp & Fallbericht & $\begin{array}{l}\text { Evaluation mo- } \\
\text { lekularer Typisie- } \\
\text { rungsmethoden }\end{array}$ & Fallbericht & Fallbericht & Fallbericht & $\begin{array}{l}\text { Fall-Kontroll- } \\
\text { Studie }\end{array}$ \\
\hline $\begin{array}{l}\text { Typisierung der Iso- } \\
\text { late }\end{array}$ & $\mathrm{Ja}$ & $\mathrm{Ja}$ & $\mathrm{Ja}$ & $\mathrm{Ja}$ & Nein & Ja \\
\hline $\begin{array}{l}\text { Methode der Typi- } \\
\text { sierung }\end{array}$ & $\begin{array}{l}\text { PFGE, RAPD, } \\
\text { Plasmid DNA-Typi- } \\
\text { sierung }\end{array}$ & rep-PCR, PFGE & PFGE & PFGE & - & PFGE \\
\hline $\begin{array}{l}\text { Patienten mit Koloni- } \\
\text { sation oder Infektion }\end{array}$ & $\mathrm{kA}$ & 16 & 10 & 7 & 6 & 57 \\
\hline $\begin{array}{l}\text { Patienten mit Koloni- } \\
\text { sation }\end{array}$ & $\mathrm{kA}$ & 10 & 1 & 6 & 1 & 37 \\
\hline $\begin{array}{l}\text { Patienten mit Infek- } \\
\text { tion }\end{array}$ & 7 & 6 & 9 & 1 & 5 & 20 \\
\hline Infektions-rate [\%] & $\mathrm{kA}$ & 38 & 90 & 14 & 83 & 35 \\
\hline Art der Infektion & LOS & $\begin{array}{l}\text { LOS, Konjunktivitis, } \\
\text { UTI, Nabelinfek- } \\
\text { tion }\end{array}$ & $\begin{array}{l}\text { LOS Pneumonie, } \\
\text { UTI, Weichteilin- } \\
\text { fektion }\end{array}$ & $\mathrm{kA}$ & LOS & LOS \\
\hline Letalität [\%] & 0 & $\mathrm{kA}$ & 33 & 0 & $\begin{array}{l}40^{\mathrm{a}} \\
\text { wahrscheinlicher } \\
\text { Zusammenhang }\end{array}$ & 45 \\
\hline \multicolumn{7}{|c|}{$\begin{array}{l}\text { NICU Neonatologische Intensivpflegestation, IMC intermediate care, SC standard care, MRGN multiresistente gramnegative Erreger, PFGE Pulsfeld-Gelelektrophorese, } \\
\text { RAPD random amplification of polymorphic DNA, rep-PCR repetitive-sequence-based polymerase chain reaction, LOS "Late-onset"-Sepsis, UTI Harnwegsinfektion, } \\
\text { kA keine Angaben } \\
\text { awahrscheinlicher Zusammenhang }\end{array}$} \\
\hline
\end{tabular}

MacDonald et al. [26] identifizierten als Quelle der nosokomialen Transmission eine Umgebungskontamination mit Wassertröpfchen im Umkreis von ca. 1,2 $\mathrm{m}$ aus dem Abluftventil eines HFO (high-frequency oscillator)-Beatmungsgeräts (Sensormedics 3100). S. marcescens wurde aus einem Abluftventil des HFOBeatmungsgeräts sowie aus der „Wasserpfütze“ auf dem Boden unter dem Ventil angezüchtet. Ein Simulationsexperiment mit fluoreszierender Flüssigkeit zeigte eine Dispersion von Tröpfchen über eine Distanz von ca. 1,2 m während der Oszillator in Betrieb war.

Während des von Polilli et al. [27] beschriebenen Ausbruches kam es vermutlich zu einer Übertragung ausgehend von einem aufgenommenen Neugeborenen mit Sepsis. Die umfassende mikrobiologi- sche Umgebungsuntersuchung ergab den Nachweis von Isolaten von $S$. marcescens an zwei Seifenspendern. Es wurde vermutet, dass es wahrscheinlich zur Übertragung zu und von den Seifenspendern durch Hände kam, wenngleich dies nicht durch den Erregernachweis an den Händen des Personals belegt werden konnte.

Maltezou et al. [20] verglichen in einer retrospektiven Fall-Kontroll-Studie $\mathrm{Pa}$ tienten mit und ohne Nachweis von $S$. marcescens, die während desselben Zeitraums hospitalisiert waren: Fallgruppe: 17 Patienten (18 \%; 13 kolonisiert, vier mit Infektion); Kontrollgruppe: $77 \mathrm{~Pa}$ tienten (82\%). Der einzig signifikante Risikofaktor für die Besiedlung oder Infektion mit $S$. marcescens in der multivariaten Analyse war die parenterale Ernährung (TPE). Die Formula-Nahrung und die TPE wurden in einem separaten Raum außerhalb der NICU von zwei Pflegeassistentinnen zubereitet. Die Umgebungsuntersuchung ergab den Nachweis von S. marcescens u. a. im Siphon der „Milchküche“, in der auch die TPE hergestellt wurde („PFGE type VIII“; „prevalent clinical clone“). Bei der direkten Beobachtung der Arbeitsabläufe durch das Infektionskontrollteam wurden Lücken in der Hände- und Umgebungsdesinfektion beobachtet, z. B. bestand keine eindeutige Trennung zwischen sauberen und kontaminierten Materialien. Die Autoren halten eine Kontamination von TPE und Formula-Nahrung für die wahrscheinlichste Quelle der konsekutiven S. marcescens-Ausbrüche. Zusätzlich bestand auf der NICU eine chronische personelle Unterbesetzung. 


\begin{tabular}{|ll}
\hline Tab. 2 Maßnahmen zur Kontrolle der Ausbrüche durch S. marcescens \\
\hline Autor & Weitere Maßnahmen \\
\hline Arslan et al. [23] & $\begin{array}{l}\text { Infektionskontrollmaßnahmen: Händehygiene, Handschuhe, Reinigung } \\
\text { der Umgebung und Desinfektion; empirische (kalkulierte) Therapie der } \\
\text { LOS: Ampicillin/Sulbactam (150 mg/kg) plus Amikacin (15 mg/kg), nach } \\
\text { dem Ausbruch Umstellung auf Meropenem/Amikacin }\end{array}$ \\
\hline Ligozzi et al. [24] & $\begin{array}{l}\text { Barrieremaßnahmen bei Kontakt, intensivierte Reinigungs- und Desinfek- } \\
\text { tionsmaßnahmen }\end{array}$ \\
\hline Bayramoglu et al. [25] & $\begin{array}{l}\text { Verstärkte Infektionskontrollmaßnahmen, Händehygiene, Desinfektion } \\
\text { der Umgebung }\end{array}$ \\
\hline MacDonald et al. [26] & $\begin{array}{l}\text { Verstärkte Infektionskontrollmaßnahmen und Desinfektion der Umge- } \\
\text { bung, Händehygiene, Barrieremaßnahmen bei Kontakt; } \\
\text { Einbau einer zusätzlichen Sekretfalle am HFO-Auslass zur Vermeidung der } \\
\text { Umgebungskontamination; } \\
\text { Einberufung eines multidisziplinären Ausbruchsmanagementeams }\end{array}$ \\
\hline Polilli et al. [27] & $\begin{array}{l}\text { Strikte Anwendung von Hygiene- und Kontrollmaßnahmen, Händehygie- } \\
\text { ne, Einmalhandschuhe }\end{array}$ \\
\hline Maltezou et al. [20] & $\begin{array}{l}\text { Neue Hygienepläne, Neuorganisation der Herstellung von Formula-Nah- } \\
\text { rung und TPE, strikte Trennung von sauberen und unsauberen Bereichen, } \\
\text { intensivierte Umgebungsdesinfektion, Austausch aller Siphons, Desinfek- } \\
\text { tion der Siphons mit 10\% Natrium-Hypochlorid, Raumdesinfektion im } \\
\text { Intensivbereich mit 5 \% Wasserstoffperoxid }\end{array}$ \\
\hline
\end{tabular}

\section{Maßnahmen zur \\ Ausbruchskontrolle}

Zur Eindämmung der Ausbrüche wurde in allen hier diskutierten Studien eine Kontaktisolierung und Kohortierung der besiedelten oder infizierten Patienten und eine gezielte Schulung des Personals einschließlich Händehygiene durchgeführt (siehe - Tab. 2). Ligozzi et al. [24] und MacDonald et al. [26] kohortierten zusätzlich auch das Personal, bei Maltezou et al. [20] erfolgte dies intermittierend. $\mathrm{Zu}$ einer vorübergehenden SchlieBung der NICU für Neuaufnahmen kam es bei Arslan et al. [23], bei MacDonald et al. [26] und bei Polilli et al. [27]. Ligozzi et al. [24] berichteten über eine Begrenzung der Zahl von Neuaufnahmen in die NICU während des Ausbruchs. Bei Maltezou et al. [20] wurde die NICU während der Ausbrüche jeweils für 4-8 Wochen für externe Aufnahmen geschlossen und blieb lediglich für im eigenen Krankenhaus geborene Neugeborene geöffnet.

Bei Arslan et al. [23] wurde nach dem Ausbruch das Protokoll für die Herstellung und Lagerung parenteraler Ernährungslösungen optimiert und das zuständige Personal erhielt eine spezielle Schulung. Zusätzlich wurde eine kontinuierliche Surveillance und ein Infektionskontrollkomitee etabliert. Ligozzi et al. [24] haben u. a. auf künstliche Fingernägel beim Personal geachtet, äußern sich aber nicht über geeignete Interventionen zur Prävention von nosokomialen Transmissionen durch kontaminierte (gepoolte) Spenderinnenmilch. MacDonald et al. [26] entwickelten eine zusätzliche Sekretfalle und später auch einen Filter, um die vom Abluftventil des HFO-Beatmungsgeräts abgegebenen Tröpfchen aufzufangen.

\section{Ausbrüche durch Klebsiella pneumoniae}

\section{Ausgangssituation}

Ruiz et al. [28] beschrieben einen Ausbruch durch 2MRGN NeoPäd Klebsiella pneumoniae (ESBL, CTX-M-15, intermediär sensibel für Ciprofloxacin, sensibel für Levofloxacin) in einer NICU in Spanien von März bis Mai 2008. Drei Frühgeborene mit einem Gestationsalter $\leq 29$ Wochen und assoziierten Risikofaktoren entwickelten eine Infektion, zwei von drei Kindern verstarben im Kontext der Infektion (Letalität 67 \%). Zusätzlich wurde bei sieben Patienten mit einem Gestationsalter $>32$ Wochen eine Kolonisation festgestellt (Infektionsrate insgesamt 30 \%). In dem von Guyot et al. [29] beschriebenen Ausbruch durch K. pneumoniae (ESBL) von Februar bis Juni 2010 in einer NICU in Frankreich waren 23 Neugeborene, 22 mit Kolonisation, ein Kind mit Infektion (Infektionsrate $4 \%$ ), betroffen. Während dieser Zeit wurden insgesamt 263 Patienten auf die neonatologische Station aufgenommen. Beschrieben wurde ein Indexpatient, mit vaginaler Kolonisation der Mutter. Die Mutter wurde in der 25. Schwangerschaftswoche mit vorzeitigem Blasensprung aufgenommen und i.v. mit Cefotaxim behandelt. Nachfolgend wurde bei weiteren 22 Patienten eine Kolonisation/Infektion festgestellt. Ab März wurde bei allen Neugeborenen ein wöchentliches Screening (Rektalabstrich) durchgeführt. Bei positivem Ergebnis wurden die Patienten kontaktisoliert. Eine Fall-Kontroll-Studie (23 Patienten in der Fallgruppe/240 Patienten in der Kontrollgruppe) ergab, dass der Einsatz von Protonenpumpeninhibitoren (OR 11,69; CI95 3,97-34,39; $p<0,001$ ) und von Cefotaxim (OR 3,01; CI95 1,09$8,33 ; p=0,04)$ unabhängige Risikofaktoren für die Kolonisation oder Infektion mit dem Ausbruchsisolat waren.

Rettedal et al. [30] berichteten über einen Ausbruch durch K. pneumoniae (ES$\mathrm{BL}$ ) in einer NICU in Norwegen von November 2008 bis April 2009. Insgesamt waren 58 Kinder betroffen, wobei lediglich bei einem Kind eine "Late-onset"Sepsis diagnostiziert wurde. Acht kolonisierte Frühgeborene mit kompliziertem Verlauf wurden für mehr als drei Monate außerhalb der NICU weiter im Krankenhaus behandelt und kontaktisoliert (90205 Tage). Alle Kinder blieben trotz des zum Teil sehr langen Beobachtungszeitraumes bis zur Entlassung mit dem Ausbruchsisolat besiedelt.

Tamma et al. [19] berichteten über einen Ausbruch durch K. pneumoniae (ESBL, CTX-M; 3MRGN), der in fünf Monaten des Jahres 2011 in einer NICU (42 Betten) ${ }^{6}$ stattfand. Zu Beginn des Ausbruchs waren $35 \%$ aller Patienten mit dem Ausbruchsisolat besiedelt. Im Verlauf wurden 31 Patienten kolonisiert, bei zehn Patienten kam es zu einer Infektion (Infektionsrate $32 \%$ ), an deren Folgen fünf Kinder verstarben (Letalität $50 \%$ ). In einem Ausbruch über zwei Monate in einer NICU in Italien (Fabbri

\footnotetext{
6 Pranita Tamma ist eine führende pädiatrische Infektiologin aus dem Johns Hopkins Medical Universitätskrankenhaus in Baltimore, USA; der Ausbruch fand wahrscheinlich in Al Ain, in den Vereinigten Arabischen Emiraten statt.
} 
et al. 2013) durch K. pneumoniae (resistent gegen Ampicillin/Piperacillin) wurde bei sechs Patienten eine primäre Blutstrominfektion durch K. pneumoniae festgestellt [21]. - Tab. 3 fasst wichtige Informationen und Daten zu diesen Ausbrüchen zusammen.

\section{Ausbruchsuntersuchung}

Ruiz et al. [28] führten unter anderem eine Antibiotikaresistenztestung und eine molekulare Typisierung durch. Das Ausbruchsmanagementteam initiierte ein Surveillance-Programm mit wöchentlichen Abstrichen (rektal und pharyngeal, zum Teil auch axillär). Im Zeitraum zwischen 17. März und 14. Mai 2008 wurden 55 Neugeborene wurden untersucht, bei sieben Patienten (13\%) wurde eine Kolonisation festgestellt. Alle K. pneumoniae-Isolate der zehn Patienten zeigten den gleichen Resistenzphänotyp und in der PFGE ein nicht zu unterscheidendes Muster. In in-vitro-Konjugationsversuchen gelang es, eines von zwei involvierten Plasmiden mit bestimmten Resistenzgenen von $K$. pneumoniae auf E. coli zu transformieren. Ob und unter welchen Bedingungen ein solcher Austausch von mobilen Resistenzgenen zwischen unterschiedlichen gramnegativen Spezies auch im Gastrointestinaltrakt der besiedelten Patienten stattfindet, ist häufig ungeklärt.

Guyot et al. [29] setzten drei verschiedene molekulare Typisierungsmethoden (Raman Spektroskopie, PFGE, rep-PCR) zur Identifizierung der genetischen Beziehung zwischen den Isolaten ein. Insgesamt wurden $30 \mathrm{~K}$. pneumoniae-Isolate von klinischen, Screenings- und Umgebungsproben untersucht. In keiner der untersuchten Muttermilchproben wurde das Ausbruchsisolat nachgewiesen. $K$. pneumoniae wurde an den Türgriffen, in einem Siphon und auf einer Tischplatte in einem Zimmer nachgewiesen, in dem zwei „positive“ Kinder behandelt wurden. Es handelte sich um zwei konsekutive Ausbrüche, wobei es möglicherweise zu einem horizontalen Transfer der Plasmidkodierten Resistenzgene zwischen den beiden Klonen gekommen war.

In der Studie von Rettedal et al. [30] wurden zu Beginn des Ausbruchs ESBLbildende K. pneumoniae bei drei Frühgeborenen mit extrem niedrigem Geburts- gewicht nachgewiesen (zweimal Screening, einmal Konjunktivitis). Daraufhin wurden alle Patienten untersucht (Abstrich rektal, konjunktival, nasopharyngeal); zu diesem Zeitpunkt waren 22 von 24 Patienten (92 \%) mit ESBL-bildenden K. pneumoniae besiedelt. Zusätzlich wurde ein Screening bei neu aufgenommenen Patienten (rektal, konjunktival, nasopharyngeal), der Umgebung und beim Personal durchgeführt. Auch bereits entlassene Familien wurden zum Screening der ehemaligen Patienten (Rektalabstrich) einbestellt. Bei 25 der 58 kolonisierten Patienten (alle im Rektalabstrich positiv) wurden zusätzlich Proben konjunktival und nasopharyngeal entnommen. Zwei der 25 konjunktivalen und drei der 25 nasopharyngealen Proben waren positiv für $K$. pneumoniae. In Muttermilchproben eines wahrscheinlichen Indexfalls wurde das Ausbruchsisolat vor und nach Verlegung aus einem anderen Krankenhaus nachgewiesen. K. pneumoniae wurde in der Muttermilch bei drei von 18 untersuchten Müttern kolonisierter Kinder und aus Umweltproben (33 von 502, hauptsächlich aus Siphons) isoliert. Eine positive Probe stammte von einer Muttermilchpumpe. Bei 30 Pflegekräften, die am Screening freiwillig und anonym teilnahmen, war das Ergebnis negativ. In der molekularen Analyse zeigten 58 von 60 Isolaten (58 aus Stuhlproben, je eines aus Blutkultur und Muttermilchprobe) nicht unterscheidbare PFGE-Muster (Typ I).

Bei Tamma et al. [19] zeigte die PFGEAnalyse bei den ersten 22 Isolaten identische Stämme und die übrigen, nicht typisierten Isolate hatten nicht identische Resistenzprofile. Fabbri et al. [21] führten Kulturen von klinischen und Umgebungsproben sowie von den Händen des Personals und bei Patienten von Abstrichen konjunktival, anal, pharyngeal bei Aufnahme und alle $72 \mathrm{~h}$ durch. Alle $K$. pneumoniae-Isolate von Patientenproben zeigten das gleiche Antibiogramm. Aus einer Saccharoselösung zur oralen Applikation bei schmerzhaften Prozeduren wurde K. pneumoniae angezüchtet, die Zuckerlösung wurde offenbar mehreren Patienten aus dem gleichen Gebinde verabreicht (keine Mehrdosisampulle, keine Konservierung). Die rep-PCR bestätigte, dass die Isolate von den sechs Kindern und aus der Saccharoselösung zu dem gleichen Genotyp gehörten. Die Kulturen von den Händen des Personals waren negativ. Auch bei den hier beschriebenen Ausbrüchen wurde in zwei Studien ein enteraler Infektionsweg (kontaminierte Muttermilch oder Saccharoselösung zur oralen Applikation) diskutiert. Die Typisierung der Isolate erwies sich als wichtige Methode zur Untersuchung der Klonalität.

\section{Maßnahmen zur Ausbruchskontrolle}

Maßnahmen zur Kontrolle des Ausbruchs waren Kontaktisolierung [19, 2830] sowie Schulung des Personals, besonders zur Händehygiene [19, 21, 29, 30]. Eine Kohortierung der Patienten und des Personals wurde in drei Studien beschrieben [19, 28, 30]. Ruiz et al. [28] setzten außerdem Antiseptika zur Umgebungsdesinfektion vor und nach der Patientenbetreuung ein. In der Studie von Guyot et al. [29] zeigte die Evaluation bezüglich der Vorgehensweisen des Personals u. a. Mängel bei der Händehygiene und Umgebungsdesinfektion sowie einen allgemeinen Personalmangel. Außer den oben beschriebenen Maßnahmen wurden zur Eindämmung des Ausbruchs die Umgebung desinfiziert, sowie Einmalhandschuhe und Schutzkittel bei jedem Patientenkontakt eingesetzt. Pflege- und Medizinprodukte wurden den einzelnen Patienten separat zugeordnet.

Rettedal et al. [30] berichteten über verstärkte Infektionskontrollmaßnahmen zur Beendigung des Ausbruchs, u. a. Händehygiene, Handschuhe, Schutzkittel, intensivierte tägliche Desinfektion der NICU. Die Waschtischarmaturen wurden gegen „non-touch“-Armaturen ausgetauscht und Waschbeckenabflüsse dekontaminiert. Die NICU wurde für Neuaufnahmen geschlossen und vorübergehend wurde eine separate NICU mit 14 Behandlungsplätzen im gleichen Krankenhaus eröffnet. Im Verlauf wurde die ursprüngliche NICU dekontaminiert und wiedereröffnet.

In dem von Tamma et al. [19] beschriebenen Ausbruch wurde in den vorangegangenen drei Monaten die Kapazität der NICU routinemäßig um 20 \% überschritten. Im Durchschnitt bestand ein Patient- 
Tab. 3 Übersicht zu den Ausbrüchen durch K. pneumoniae

\begin{tabular}{|c|c|c|c|c|c|}
\hline Autor & Ruiz et al. [28] & Guyot et al. [29] & Rettedal et al. [30] & Tamma et al. [19] & Fabbri et al. [21] \\
\hline Land & Spanien & Frankreich & Norwegen & Naher Osten & Italien \\
\hline Setting & $\begin{array}{l}\mathrm{NICU} \text {, regionales Kran- } \\
\text { kenhaus }\end{array}$ & NICU, Universität & NICU, Universität & NICU Universität? & $\begin{array}{l}\text { NICU, regionales Kran- } \\
\text { kenhaus }\end{array}$ \\
\hline Bettenzahl NICU & $\mathrm{kA}$ & 44 & 21 & 42 & 13 \\
\hline MRGN? & $\begin{array}{l}\text { 2MRGN NeoPäd } \\
\text { (CTX-M-15) }\end{array}$ & $\begin{array}{l}\text { 2MRGN NeoPäd } \\
\text { (CTX-M-15, SHV-1 und } \\
\text { TEM-1) }\end{array}$ & $\begin{array}{l}\text { 2MRGN NeoPäd } \\
\text { (CTX-M-15) }\end{array}$ & $\begin{array}{l}\text { 3MRGN, \# für Merope- } \\
\text { nem und Amikacin }\end{array}$ & Kein MRGN \\
\hline Zeitraum & $03 / 2008-05 / 2008$ & $02 / 2010-06 / 2010$ & $11 / 2008-04 / 2009$ & $\begin{array}{l}5 \text { Monate im Jahr } 2011 \\
\text { (bis 08/2011) }\end{array}$ & 2 Monate \\
\hline Studientyp & Fallbericht & Fall-Kontroll-Studie & Fallbericht & Fallbericht & Fallbericht \\
\hline Typisierung der Isolate & $\mathrm{Ja}$ & $\mathrm{Ja}$ & Ja & $\mathrm{Ja}$ & $\mathrm{Ja}$ \\
\hline $\begin{array}{l}\text { Methode der Typisie- } \\
\text { rung }\end{array}$ & PFGE & $\begin{array}{l}\text { Raman Spektroskopie, } \\
\text { PFGE, rep-PCR }\end{array}$ & $\begin{array}{l}\text { PFGE, PCR-basierte } \\
\text { Analyse der Resistenz- } \\
\text { gene }\end{array}$ & $\begin{array}{l}\text { PFGE of Xba I digested } \\
\text { chromosome }\end{array}$ & PFGE, rep-PCR \\
\hline $\begin{array}{l}\text { Patienten mit Kolo- } \\
\text { nisation und/oder } \\
\text { Infektion }\end{array}$ & 10 & 23 & 58 & 31 & $k A$ \\
\hline $\begin{array}{l}\text { Patienten mit Koloni- } \\
\text { sation }\end{array}$ & 7 & 22 & 57 & 21 & $\mathrm{kA}$ \\
\hline Patienten mit Infektion & 3 & 1 & 1 & 10 & 6 \\
\hline Infektionsrate [\%] & 30 & 4 & 2 & 32 & $\mathrm{kA}$ \\
\hline Art der Infektion & LOS & LOS & LOS & $\begin{array}{l}\text { Meningitis, LOS, VAP, } \\
\text { Abszess intra-abdo- } \\
\text { minal }\end{array}$ & LOS \\
\hline Letalität [\%] & 67 & 0 & 0 & 50 & 0 \\
\hline
\end{tabular}

zu-Personal Verhältnis von 4:1 im Überwachungsbereich bzw. 3:1 im Intensivpflegebereich. Systematische Beobachtungen ergaben, dass in der ersten Woche des Ausbruchs die Compliance des Personals mit der hygienischen Händedesinfektion und mit der Kontaktisolierung niedrig war (ca. 40 \%). Es gab keinen vollständigen Hygieneplan in Bezug auf die Aufbereitung von Medizinprodukten und keine eindeutige Trennung potentiell kontaminierter und sauberer Utensilien.

Zusätzlich zu den oben beschriebenen Maßnahmen bestanden die Interventionen der Infektionskontrolle in der Beobachtung der Händehygiene-Compliance, der Kontaktisolierung, der Anlage von Gefäßkathetern, der Reinigung und Desinfektion sowie des Umgangs mit Muttermilch. Die Compliance mit der hygienischen Händedesinfektion und der Kontaktisolierung nahm in dieser Phase signifikant auf 82-92 \% zu. Die saubere Ausstattung wurde räumlich von der kontaminierten getrennt. „Mehrdosisentnahmen" aus Einmalampullen sowie geteilte Infusionsbeutel wurden nicht mehr zu- gelassen. Proben der unbelebten Umgebung blieben negativ. Nach der Erweiterung der NICU auf 64 Betten und einer Belegung zwischen 43 und 52 Patienten konnte der Bettenabstand vergrößert werden. Der NICU wurde mehr Personal zugewiesen, die Tätigkeiten wurden neu verteilt und die Belegung insgesamt reduziert. Ziel war eine Patient-zu-Pflegekraft Ratio von max. 2:1 im Intensivpflegebereich und max. 3:1 im Überwachungsbereich. Die Neuaufnahmen wurden auf nicht abweisbare kritisch kranke Neugeborene beschränkt. Nach August 2011 gab es keine weiteren Fälle mit K. pneumoniae-Kolonisation.

Bei Fabbri et al. [21] wurde nach dem Auftreten der ersten vier Infektionen eine Reihe von Maßnahmen implementiert. Die tägliche Begehung der NICU durch das Infektionskontrollteam und die Evaluation der angeordneten Kontrollmaßnahmen mithilfe einer Checkliste sollten die Compliance beim Behandlungsteam sicherstellen.

Aufnahmen in die NICU wurden zeitweise ausgesetzt. Die systematische Be- gehung durch das Hygienefachpersonal ergab Hinweise auf Hygienefehler (z. B. Verwendung von lokalanästhetischen Salben für mehrere Patienten, keine saubere Abgrenzung eines separaten Arbeitsbereichs zur Herstellung von i.v. Lösungen, Verwendung eines Flächendesinfektionsmittels mit zu geringer Konzentration usw.). Nach der Identifikation von Lücken in der Infektionskontrollstrategie wurden folgende Maßnahmen angepasst oder intensiviert: spezifische/rechtzeitige Antibiotikatherapie, Einzeldosenverordnungen, Händehygiene, Desinfektionsmittelspender an jedem Patientenplatz, fest zugeordnetes Tablett mit medizinischen und hygienischen Instrumenten des täglichen Gebrauchs, korrekte Aufbereitung von Medizinprodukten, Implementierung von Ablaufschemata bezüglich hygienischer Maßnahmen und Abfallentsorgung bei Infektionen und Einrichtung reiner Arbeitsbereiche für aseptisches Arbeiten bzw. für $\mathrm{Zu}$ bereitungen. Diese Maßnahmen beendeten den Ausbruch. 
Ausbrüche durch

Acinetobacter baumannii

\section{Ausgangssituation}

McGrath et al. [31] analysierten retrospektiv einen Ausbruch durch ein 4MRGN Acinetobacter baumannii-Isolat in einer NICU (36 Betten) in den USA. Dieser Ausbruch dauerte von November 2008 bis Januar 2009. Bei sechs Frühgeborenen mit einem Geburtsgewicht $\leq 1000$ g kam es zu einer Infektion. Bei einem Kind wurde eine Konjunktivitis diagnostiziert, bei einem anderen Kind eine Konjunktivitis und eine Beatmungsassoziierte Pneumonie (VAP), bei drei Kindern eine Pneumonie (zweimal VAP) und bei einem weiteren Kind eine Bakteriämie. Ein Kind verstarb, jedoch nicht im Zusammenhang mit der Infektion.

Die dramatischen Konsequenzen eines nicht zeitnah kontrollierten Ausbruchs durch ein 4MRGN A. baumannii-Isolat zeigt die Studie von Hosoglu et al. [32] (NICU eines türkischen regionalen Krankenhauses mit 50 Behandlungsplätzen, November 2006 bis August 2007). Während des Ausbruchs wurde bei 64 Frühund Neugeborenen eine Blutstrominfektion (BSI) durch A. baumannii und bei 63 Patienten eine Kolonisation mit $A$. baumannii diagnostiziert. Zur multivariaten Analyse von Risikofaktoren führten die Autoren eine Fall-Kontroll-Studie durch. In die Studie eingeschlossen wurden alle 64 Patienten mit A. baumannii-BSI und 128 Kontrollpatienten. Eine verlängerte Liegedauer in der NICU (OR 1,15; CI95 1,07-1,23) und eine Reintubation (OR 38,62; CI95 12,66-117,87) waren unabhängige Risikofaktoren für das Auftreten einer BSI durch das Ausbruchsisolat. Von den Patienten mit einer Infektion verstarben 53 (83\%), verglichen mit 51 (40 \%) Kindern in der Kontrollgruppe. Die „attributable mortality“ konnte nicht exakt beschrieben werden. Wichtige Informationen und Daten zu diesen Ausbrüchen sind in der $\bullet$ Tab. 4 zusammengefasst.

\section{Ausbruchsuntersuchung und Maßnahmen zur Ausbruchskontrolle}

In der NICU in Michigan, USA [31] wurdekeine Umgebungsuntersuchung durch- geführt, ein einmaliges Screening aller $\mathrm{Pa}$ tienten der Einheit (axillärer Abstrich plus respiratorisches Sekret) ergab negative Befunde. Es gab kein Konzept des Übernahmescreenings bei Verlegungen aus anderen Krankenhäusern. Als Übertragungsweg wurde eine Weiterverbreitung durch Personal vermutet, weil die Beobachtung der Arbeitsabläufe Hygienefehler zeigte. Zweimal „erwarben“ die Patienten den 4MRGN A. baumannii an Behandlungsplätzen, die zuvor mit einem kolonisierten Patienten belegt waren (Problem der Flächendesinfektion?). Bei dem Ausbruch in dem türkischen Distriktkrankenhaus [32] waren drei von 20 (15\%) (unangemeldet abgenommenen) Proben von den Händen der Pflegekräfte sowie 23 von 69 (33\%) Proben aus der NICU-Umgebung der Patienten positiv (Tische, Geräte zur Infusion von i.v. Lösungen, Intubationsund Beatmungszubehör, Inkubatoren). Vermutlich kam es u. a. bei der Reintubation mit kontaminierten Spekula (unzureichende Aufbereitung, kontaminierte Hände) zur Übertragung des Erregers. Auch hier wurden zur Eindämmung der Ausbrüche die Patienten isoliert/kohortiert (Patienten und Personal); das Personal wurde insbesondere in Bezug auf eine adäquate Händedesinfektion geschult. Bei McGrath et al. [31] war der Indexpatient zuvor wegen einer MRSA-Infektion kontaktisoliert worden, aufgrund von räumlicher Enge, nur begrenzt verfügbarem Personal und der Notwendigkeit der Überwachung jedoch nicht in einem Einzelzimmer. Erst nach dem dritten Nachweis wurde ein Isolierzimmer zur Kohortierung der A. baumannii-positiven Patienten eingerichtet. Zusätzlich wurden die Händedesinfektion, die Beachtung aseptischer Techniken bei invasiven Maßnahmen und bei der Umgebungsdesinfektion intensiviert. Die Dokumentation (z. B. der Vitalzeichen) in der Patientenkurve wurde nicht mehr unmittelbar am Behandlungsplatz durchgeführt. Es fanden regelmäßige Konferenzen zwischen den Neonatologen, Infektiologen, Epidemiologen und der Pflegedienstleitung statt.

In der Publikation von Hosoglu et al. [32] wurden zur Kontrolle des Ausbruchs zusätzliche Handwaschplätze installiert, das Konzept der Reinigung und Desinfektion der Patientenumgebung wurde ver- bessert, die Aufbereitung der Medizinprodukte wurde überprüft, die Arbeitsabläufe der NICU wurden reorganisiert und es wurde ein Antibiotika-Stewardship-Programm implementiert. Es kam zur Einschränkung von Neuaufnahmen, außerdem wurde eine Reduktion der Arbeitsbelastung empfohlen. Die Kontrolle des Ausbruchs wurde durch eine Patientenüberbelegung sowie durch die medizinische Notwendigkeit der Patientenversorgung in der NICU erschwert. Einen temporären Aufnahmestopp hielten die Autoren in beiden Kliniken anscheinend nicht für möglich, weil es sonst zu gravierenden Versorgungsengpässen gekommen wäre.

\section{Ausbrüche durch \\ Pseudomonas aeruginosa}

\section{Ausgangssituation}

Zur Untersuchung eines Ausbruchs durch $P$. aeruginosa wurden von April bis Juni 2006 in einer prospektiven Studie von Naze et al. [33] einmal pro Woche bei insgesamt 100 Patienten, die während dieses Zeitraumes in die NICU aufgenommen wurden, Abstriche von Stuhl und Konjunktiven (bei einigen auch Trachealsekret) entnommen. Bei 42 Patienten war mindestens eine Probe positiv für $P$. aeruginosa, 40 Patienten waren kolonisiert und zwei hatten eine Infektion. Ein Patient verstarb an einer Infektion durch das Ausbruchsisolat. Yapicioglu et al. [34] berichteten über einen Ausbruch in einer NICU in der Türkei. Insgesamt wurde bei 12 Patienten eine Infektion mit $P$. aeruginosa diagnostiziert (8-mal LOS, 4-mal VAP). Sieben Patienten mit einer Blutstrominfektion verstarben, davon zwei Kinder infolge einer $P$. aeruginosa-Infektion. Bei einem Ausbruch durch P. aeruginosa in einer NICU in Spanien (MolinaCabrillana et al. 2013) von Oktober 2011 bis Januar 2012 wurde bei zehn neonatologischen Patienten eine Infektion ( $n=9$; Pneumonie, Konjunktivitis) oder Besiedlung $(n=1)$ mit $P$. aeruginosa festgestellt [22]. - Tab. 5 fasst wichtige Informationen und Daten zu diesen Ausbrüchen zusammen. 
Tab. 4 Übersicht zu den Ausbrüchen durch A. baumannii

\begin{tabular}{lll}
\hline Autor & McGrath et al. [31] & Hosoglu et al. [32] \\
\hline Land & USA & Türkei \\
\hline Setting & NICU, Lehrkrankenhaus & NICU, regionales Krankenhaus \\
\hline Bettenzahl NICU & 36 & 50 \\
\hline MRGN? & 4 MRGN & 4 MRGN \\
\hline Untersuchungszeitraum & $11 / 2008-01 / 2009$ & $11 / 2006-08 / 2007$ \\
\hline Studientyp & Fallbericht & $\begin{array}{l}\text { Retrospektive und prospekti- } \\
\text { ve Fall-Kontroll-Studie }\end{array}$ \\
\hline Typisierung der Isolate & Ja, nur 1 Isolat & Ja \\
\hline Methode der Typisierung & PFGE & PFGE \\
\hline $\begin{array}{l}\text { Patienten mit Kolonisation und/ } \\
\text { oder Infektion }\end{array}$ & 6 & 127 \\
\hline Patienten mit Kolonisation & 0 & 63 \\
\hline Patienten mit Infektion & 6 & 64 \\
\hline Infektionsrate [\%] & 100 & 50 \\
\hline Art der Infektion & $\begin{array}{l}\text { Konjunktivitis (2), Pneumonie } \\
(4, \text { davon 3-mal VAP), LOS (1) }\end{array}$ & Blutstrominfektion (LOS) \\
\hline Letalität & $0 \%$ & kA \\
\hline $\begin{array}{l}\text { Fallgruppe: 53 Patienten (83 \%); Kontrollgruppe: 51 Patienten (40 \%); Letalität (,attributable mortality“) unklar } \\
\text { NICU Neonatologische Intensivpflegestation, MRGN multiresistente gramnegative Erreger, PFGE Pulsfeld-Ge- } \\
\text { lelektrophorese, VAP Beatmungsassoziierte Pneumonie, LOS „Late-onset“-Sepsis, KA keine Angaben }\end{array}$ \\
\hline
\end{tabular}

\section{Ausbruchsuntersuchung und Maßnahmen zur Ausbruchskontrolle}

In allen drei Studien konnte P. aerugino$s a$ aus Umgebungsproben isoliert werden: Bei Naze et al. [33] wurde P. aeruginosa unter anderem aus Mineralwasserflaschen, aus Milch, die mit diesem Wasser zubereitet wurde und von Rührbesen zum Mischen von Wasser und Milch isoliert. Mit molekulargenetischen Methoden wurde die Klonalität der P. aeruginosa-Isolate nachgewiesen und die Kontamination von zwei Chargen eines Mineralwassers, das für die Zubereitung von Formula-Nahrung verwendet wurde, als Quelle des Ausbruchs identifiziert. Das Mineralwasser war ab Werk kontaminiert, weil dort - nach vorübergehendem Stopp der Abfüllung - keine mikrobiologisch überprüfte Reinigung der Abfüllanlage erfolgt war. Die Verwendung einer anderen Mineralwassermarke beendete den Ausbruch. Bei der Ausbruchsuntersuchung von Yapicioglu et al. [34] wurden sechs Monate vor dem Ausbruch in vier Patientenzimmern und einem Labor konventionelle Waschtischarmaturen gegen elektronisch gesteuerte Modelle ausgewechselt, um Handkontakte mit der Armatur beim Händewaschen zu vermeiden. $P$. aeruginosa wurde aus einer Flüssighandseife und aus Filter- und Wasser- proben von elektronischen Waschtischarmaturen in Patientenzimmern und Laboratorien isoliert. Nachdem die elektronischen Waschtischarmaturen als mögliche Infektionsquelle entdeckt wurden, wurden zusätzliche Kontrollmaßnahmen einschließlich eines alkoholischen Einreibepräparats für die Händedesinfektion und Tragen von Handschuhen nach dem Händewaschen eingesetzt. Die elektronischen Waschtischarmaturen wurden entfernt und durch mit Ellbogen zu bedienenden Armaturen ersetzt. Danach kam es zu einem Rückgang der ,attack rate". Nicht alle klinischen Isolate in dieser Studie wurden typisiert. Die Autoren vermuten, dass es sich um einen polyklonalen Ausbruch handelte und dieser durch die elektronischen Waschtischarmaturen verursacht wurde. Bei dem durch MolinaCabrillana et al. [22] beschriebenen Ausbruch wurde an den Händen des Personals kein $P$. aeruginosa nachgewiesen. $P$. aeruginosa fand sich jedoch im Leitungswasser, das auch in Flaschenwärmern zum Anwärmen von Muttermilch und von Formula-Nahrung verwendet wurde. Diese Flaschenwärmer wurden zweimal pro Woche desinfiziert, die Wechselfrequenz des Wassers war nicht eindeutig definiert. Nachdem steriles Wasser anstelle von Leitungswasser in den Flaschenwärmern eingesetzt wurde, traten keine weiteren Fälle mehr auf. Obwohl keine molekulare Typisierung der Ausbruchsisolate durchgeführt wurde, konnte der Ausbruch durch Umgebungsuntersuchungen und die daraus abgeleiteten Schlussfolgerungen beendet werden. Bei Yapicioglu et al. [34] und Molina-Cabrillana et al. [22] wurden als weitere Maßnahmen zur Eindämmung des Ausbruchs die Patienten kontaktisoliert und kohortiert sowie Schulungen des Personals durchgeführt. Zusätzlich wurde bei dem von Yapicioglu et al. [34] beschriebenen Ausbruch die Station soweit möglich vier Wochen für Neuaufnahmen geschlossen.

\section{Diskussion}

Ausbrüche auf neonatologischen Intensivstationen treffen eine besonders vulnerable Patientenpopulation und müssen separat von Ausbrüchen in anderen Intensivstationen analysiert werden [1]. Die hier vorgestellten Ergebnisse einer systematischen Literaturrecherche der internationalen Fachliteratur von 2010 bis Februar 2013 bestätigen die nach wie vor besondere Bedeutung von Infektionsausbrüchen durch bestimmte gramnegative Infektionserreger für die Patienten und das Behandlungsteam in NICUs.

Aus den hier zusammengestellten Arbeiten lässt sich nicht herleiten, ob Ausbrüche, die durch MRGN verursacht werden, in NICUs insgesamt zunehmen. Wahrscheinlich werden Ausbrüche durch 3MRGN oder 4MRGN häufiger publiziert als solche durch gramnegative Erreger ohne Multiresistenz (reporting bias) [1,35].

Die hier vorgestellte Zusammenstellung von Ausbrüchen unterstreicht die Bedeutung bereits bekannter Risiken im Hygienemanagement, wie z. B.:

- die Kontamination von Seifenspendern [27],

- Verwendung von Pflegeprodukten (Salben) für mehrere Patienten [21],

- Verwendung eines Flächendesinfektionsmittels mit zu geringer Konzentration [21],

- die Kontamination oraler Medikamente (hier: Zuckerlösung) und die unzulässige Verwendung von Einmalgebinden als „Mehrdosisbehältnis" [21], 
Tab. 5 Übersicht zu den Ausbrüchen durch P. aeruginosa

\begin{tabular}{|llll}
\hline Autor & Naze et al. [33] & Yapicioglu et al. [34] & Molina-Cabrillana et al. [22] \\
\hline Land & Frankreich & Türkei & Spanien \\
\hline Setting & NICU, Universität & NICU, Universität & NCU, Universität \\
\hline Bettenzahl NICU & 10 (in einer 28-Bettenabteilung) & $12-14$ (in einer 25-Bettenabteilung) & $\begin{array}{l}15 \text { NICU und 10 IMC } \\
\text { (in einer 55-Betten-abteilung) }\end{array}$ \\
\hline MRGN? & kA & 8 von 12 invasiven Isolaten: 4MRGN & Kein MRGN \\
\hline Untersuchungszeitraum & 04/2006-06/2006 & 06/2010-11/2010 & $10 / 2011-01 / 2012$ \\
\hline Studientyp & Prospektive Studie & Fallbericht & Fallbericht \\
\hline Typisierung der Isolate & Ja & Ja & Nein \\
\hline Methode der Typisierung & Multiple-locus VNTR typing with & PFGE & - \\
\hline $\begin{array}{l}\text { Patienten mit Kolonisation und/ } \\
\text { oder Infektion }\end{array}$ & HRMA & kA & 10 \\
\hline Patienten mit Kolonisation & 40 & & 1 \\
\hline Patienten mit Infektion & 2 & kA & 9 \\
\hline Infektionsrate [\%] & 5 & 12 & 90 \\
\hline Art der Infektion & LOS & Unklar & Pneumonie (z. T. VAP), Konjunktivitis \\
\hline Letalität [\%] & 50 & LOS, VAP & 0 \\
\hline $\begin{array}{l}\text { NICU Neonatologische Intensivpflegestation, IMC intermediate care, MRGN multiresistente gramnegative Erreger, VNTR variable number tandem repeat, HRMA high- } \\
\text { resolution melting analysis, PFGE Pulsfeld-Gelelektrophorese, LOS „Late-onset"-Sepsis, VAP Beatmungsassoziierte Pneumonie, } \text { kA keine Angaben }\end{array}$
\end{tabular}

- die Verwendung von Flaschenwärmern mit Leitungswasser [22],

- die Zubereitung von Formula-Nahrung ohne ausreichenden Hygienestandard [20],

- die fehlende mikrobiologische Kontrolle und das Pooling von Ammenmilch [24, 36],

- die nicht streng aseptische Zubereitung von Infusionslösungen, v. a. zur parenteralen Ernährung [20, 23, 37].

Andererseits ergaben sich jedoch auch Hinweise auf bisher wenig bekannte Reservoire, wie z. B. der Abluftschenkel von HFO-Beatmungsgeräten [26] oder Mineralwasser, das zur Zubereitung von Formula-Nahrung verwendet wurde [33]. Gespendete Muttermilch kann aus infektiologischer Sicht problematisch sein und sollte keinesfalls ohne mikrobiologische Freigabe gepoolt/verabreicht werden [36].

Bei vermehrten nosokomialen Transmissionen oder Ausbrüchen des „Feuchtkeims" $P$. aeruginosa müssen Reservoire in Wasser, das mit den Patienten (oder mit den Händen des Personals) direkt oder indirekt in Kontakt kommt, konsequent ausgeschlossen werden [38, 39]. Walker et al. [40] berichteten vor kurzem über invasive $P$. aeruginosa-Infektionen in mehreren NICUs in Irland, die mit elektronisch gesteuerten, „non-touch“-Wasch- tischarmaturen [34] in Verbindung standen. Dies entspricht den Berichten von Yapicioglu et al. 2012 [34] und weiterer Autoren [41]. Erstaunlicherweise stellten Rettedal et al. [30] im Rahmen des Ausbruchsmanagements auf solche „nontouch"-Armaturen um.

Bei Betrachtung der klinischen Manifestationen (Anteil der Patienten mit einer Infektion im Verlauf) ist eine Konjunktivitis in Bezug auf den klinischen Schweregrad und das Management nicht mit einer Beatmungsassoziierten Pneumonie oder einer Sepsis gleichzusetzen. Die Studie von McGrath et al. [31] (Ausbruch durch ein 4MRGN Acinetobacter baumannii-Isolat in einer NICU; ein Kind mit Konjunktivitis ein Kind mit Konjunktivitis und Beatmungsassoziierter Pneumonie, drei Kindern mit Pneumonie und ein Kind mit Bakteriämie) zeigt jedoch, dass eine Erregerdiagnostik bei Konjunktivitis angestrebt werden sollte. Dies kann zum einen für die lokale oder systemische Behandlung zielführend sein und des Weiteren auch Hinweise auf einen Infektionsausbruch ergeben.

Interessant an der Untersuchung von MacDonald et al. [26] ist nicht nur die besondere Quelle des Serratia-Isolates (HFO-Beatmungsgerät, Auslassventil), sondern auch das systematische proaktive Vorgehen des Ausbruchsmanage- mentteams, das die infektionsepidemiologische Relevanz von S. marcescens für NICU-Patienten frühzeitig erkannt hat [42]. Die Autoren verweisen darauf, dass Hygienerisiken beim Einsatz der HFOBeatmung durchaus beschrieben sind [43], jedoch nicht in ausreichendem Ausmaß zur Implementierung zusätzlicher Schutzmaßnahmen geführt haben. Auch das „offene Design“ ihrer NICU und der zu kleine Abstand zwischen den Behandlungsplätzen werden problematisiert.

Das offene Design von NICU-Behandlungsräumen wurde in den letzten 20 Jahren favorisiert, weil man glaubte, dass dies aus Gründen der Überwachung unter dem gegebenen Personalschlüssel günstiger sei (kurze Wege zwischen den Inkubatoren). Tatsächlich sind deshalb viele NICUs in dieser Übersicht und auch in Deutschland [44] nur bedingt in der Lage, Ausbrüche durch Einzelzimmerisolierung oder räumliche Kohortierung anzugehen [45]. Nicht jede Klinik verfügt über die Ressourcen, vorübergehend eine „separate NICU für die infizierten und kolonisierten Patienten“" mit eigenem Versorgungsteam zu etablieren [30].

Personelle Unterbesetzung bzw. eine Überbelegung der Station werden von verschiedenen Autoren der hier referierten Ausbruchsberichte als eine begünstigende Ursache für den Ausbruch angege- 
ben $[19,20,29,31,32]$. Bei Tamma et al. [19] wurden im Rahmen des Ausbruchsmanagements sehr konkrete Ziele für eine verbesserte Personalstruktur angestrebt (Patient-zu-Pflegekraft Ratio max. 2:1 im Intensivpflegebereich und max. 3:1 im Überwachungsbereich). Personalmangel bzw. Überbelegung sind wissenschaftlich gesicherte Risikofaktoren für nosokomiale Infektionen und erhöhen das Risiko von Infektionsausbrüchen $[19,46]$. Die personelle Ausstattung der Pflege unterliegt nach den vorliegenden Daten auch in deutschen NICUs einer erheblichen Schwankungsbreite [44] und ist in vielen NICUs niedriger als von den Fachgesellschaften empfohlen [47, 48]. Die aktuellen Empfehlungen des Gemeinsamen Bundesausschusses zum angestrebten Stellenschlüssel in NICUs tragen diesem Zusammenhang erstmals Rechnung und werden die Personalsituation in der neonatologischen Intensivpflege nachhaltig verbessern. Dies sollte mit einer Verbesserung der Compliance bei infektionspräventiven Maßnahmen einhergehen und die personellen Optionen beim Management von Ausbrüchen erweitern.

Ein Screening des Personals ist, im Unterschied zu vergleichbaren Studien zu MRSA [49], bei den hier analysierten Ausbrüchen durch MRGN selten ein Thema; bei Rettedal et al. ergaben sich ausschließlich negative Befunde [30].

Während des Ausbruchsmanagements wurde in mehreren hier referierten Studien eine vorübergehende Schließung der NICU für Neuaufnahmen [20, 21, 23, $26,27,34$ ] oder zumindest eine Begrenzung der Zahl von Neuaufnahmen [24] erforderlich. Die Sperrung von NICU-Behandlungsplätzen über Wochen bis Monate, bzw. deren extensiv verlängerte Belegung durch Patienten mit MRGN-Besiedlung und kompliziertem Verlauf, ist aus betriebswirtschaftlicher Perspektive eine enorme Belastung für die Klinik. Hier kommt es rasch zu Einnahmeverlusten in Höhe von mehreren $100.000 €$ (fehlende DRG-Pauschalen für die Behandlung sehr unreifer Frühgeborener). Aus der Perspektive der Krankenhausadministration ist dies ein sehr gewichtiges Argument für ein schnelles und effektives Ausbruchsmanagement, auch wenn hierdurch vorübergehend die Kosten erheblich steigen.
In den meisten in dieser Arbeit analysierten Studien wurde im Rahmen des Ausbruchsmanagements eine molekulargenetische Typisierung durchgeführt. Diese stellt ein wichtiges Instrument zur Bestätigung oder zum Ausschluss einer klonalen Beziehung zwischen den bei mehreren Patienten nachgewiesenen Isolaten dar. Keinesfalls dürfen jedoch notwendige krankenhaushygienische Interventionen bei Ausbruchsverdacht unterbleiben oder nur verzögert oder zu zögerlich umgesetzt werden, weil die exakte Typisierung der Isolate noch aussteht $[50,51]$. Sehr wahrscheinlich werden konventionelle Typisierungsmethoden in naher Zukunft durch eine Gesamtgenomsequenzierung der Isolate abgelöst bzw. ergänzt.

Häufig eingesetzte Maßnahmen zur Kontrolle der Ausbrüche waren u. a. Isolierung, Kohortierung der Patienten (teilweise auch des Personals), gezielte Schulung des Personals, einschließlich in Bezug auf Händehygiene sowie intensivierte Reinigung/Desinfektion der Umgebung. Solche Maßnahmen sollten vom Ausbruchsmanagement-team nicht nur empfohlen werden, vielmehr ist es erforderlich, dass ihre Implementierung und Umsetzung durch die medizinisch Verantwortlichen (Ärzte/Pflegedienstleitung) und das Hygienefachpersonal vor Ort überprüft und sichergestellt wird. Fabbri et al. [21] schlugen zur systematischen Begehung der NICU durch das Hygienefachpersonal eine an die Arbeitsabläufe der Station angepasste Checkliste mit krankenhaushygienisch relevanten kritischen Kontrollpunkten vor. Die Erstellung einer solchen Liste kann in deutschen NICUs anhand der KRINKO-Empfehlung von 2007 erfolgen [9], erweitert um die Aspekte der praktischen Umsetzung des mikrobiologischen Screenings und der sich aus dem Screening ergebenden Hygienemaßnahmen [11]. Ein aktueller Survey im Deutschen Frühgeborenennetzwerk zeigt, dass die meisten der 2007 empfohlenen Präventionsmaßnahmen in den befragten NICUS inzwischen zur klinischen Routine gehören [44].

Die hier relevanten Erreger nosokomialer Infektionen können, wie mehrere der hier besprochenen Berichte zeigen $[29,31,32]$, in der unbelebten Um- gebung der Patienten persistieren [52]. Daher sollten vom Hygienefachpersonal gezielt eingesetzte Umgebungsuntersuchungen und eine Überprüfung und ggf. Intensivierung der Umgebungsdesinfektion Bestandteile des Ausbruchsmanagements sein.

Dies gilt auch für Ausbrüche durch Serratia marcescens, obwohl dieser Infektionserreger bislang seltener in der unbelebten Umgebung der Patienten nachgewiesen wurde [42] und selbst umfangreiche Umgebungsuntersuchungen mitunter nur negative Ergebnisse liefern [3]. Bei drei der hier referierten Ausbrüche durch Klebsiella pneumoniae handelte es sich um ein CTX-M-15 bildendes Isolat [2830]. Solche $\beta$-Laktamasen mit erweitertem Wirkspektrum werden in den letzten Jahren zunehmend bei Enterobacteriaceae, insbesondere auch bei E. coli im ambulanten Setting (Harnwegsinfektionen) gefunden $[53,54]$.

Nach heutigem Stand des Wissens ist eine nachhaltig erfolgreiche Dekolonisierung von MRGN-besiedelten NICU-Patienten nicht möglich [55]. Der Einsatz von Aminoglykosiden oder Colistin (beides i.v. oder p.o.) zur Dekolonisierung von MRGN-besiedelten Patienten [56] sollte nicht versucht werden, weil hierunter Aminoglykosid- und Colistinresistente MRGN selektioniert werden können und dann auch diese Therapeutika für Infektionen durch 4MRGN wirkungslos werden [57]. Besiedelte Kinder bleiben demnach bis zu ihrer Entlassung ein wichtiges Reservoir der nosokomialen Transmission [30].

Die lang anhaltende Kolonisierung ist wahrscheinlich auch darin begründet, dass es sich um Bakterien handelt, die den Gastrointestinaltrakt langfristig besiedeln können [55, 58]. Insofern gelten die entsprechenden Barrieremaßnahmen stets bis zur Entlassung der Kinder und ggf. auch darüber hinaus (bei Wiederaufnahme oder in Spezialambulanzen). Inwieweit es in vivo (im gastrointestinalen Mikrobiom der Patienten) zu einem Austausch von Resistenzgenen zwischen verschiedenen Enterobacteriaceae kommen kann - wie dies z. B. von Ruiz et al. für $K$. pneumoniae und E. coli vermutet wurde [28] - ist ungeklärt. Es gibt inzwischen auch Hinweise darauf, dass MRGN von 
besiedelten Kindern auf ihre Angehörigen (auf enge Kontaktpersonen) übertragen werden können [58, 59]. Die Bedeutung dieser Befunde aus infektionsepidemiologischer Perspektive ist noch unklar.

In der Fall-Kontroll-Studie von Guyot et al. [29] waren der Einsatz von Protonenpumpeninhibitoren und von Cefotaxim unabhängige Risikofaktoren für die Kolonisation oder Infektion mit dem $K$. pneumoniae-Ausbruchsisolat. Arslan et al. [23] stellten im Verlauf des Ausbruchs ihr empirisches Therapieregime zur Therapie der "Late-onset“-Sepsis um und etablierten ein „Antibiotic Stewardship“ Team. Es gibt noch zahlreiche weitere Studien, die auf einen kausalen Zusammenhang zwischen dem Einsatz bestimmter Breitspektrumantibiotika (insbesondere von Cephalosporinen der Gruppe III) und der Prävalenz von MRGN in der jeweiligen NICU hinweisen [13, 60-62]. Auch NICUs benötigen zur langfristigen Kontrolle von MRGN nicht nur eine gute Praxis der Krankenhaushygiene sondern auch ein „Antibiotic Stewardship" Programm [11, 63]. Wichtig ist dabei auch, die Indikationen für den Einsatz z. B. von Meropenem festzulegen, damit es nicht zu einer unkritischen Zunahme der Verordnung von Carbapenemen kommt.

Die „attributable mortality“ (die der Infektion zugeschriebene Letalität) bei Ausbrüchen ist mitunter außerordentlich schwierig darzustellen, insbesondere, wenn es sich um Intensivpatienten mit kompliziertem Verlauf und um retrospektiv analysierte Daten (Fallberichte ohne Kontrollgruppen) handelt. Leider fehlt in einigen der hier analysierten Studien die Gesamtzahl der während des Ausbruchszeitraumes behandelten Kinder, sodass die Raten für Kolonisation und Infektion sowie die Letalität nicht immer bestimmt werden konnten. Außerdem ist zu vermuten, dass ein Teil der Ausbrüche auf NICUs nicht publiziert wird und eventuell ein Publikationsbias zu Gunsten von Ausbrüchen vorliegt, bei denen die Infektionsquelle gefunden werden konnte und/ oder die unter dem Einsatz verstärkter Infektionskontrollmaßnahmen zeitnah erfolgreich kontrolliert wurden. Trotzdem zeigen die verfügbaren Daten (siehe Tabellen) neben erheblichen Kolonisationsund Infektionsraten auch ein erhöhtes Ri- siko für einen tödlichen Ausgang bei den Frühgeborenen mit einer Infektion durch die hier untersuchten Erregerspezies. Bei Serratia marcescens besteht dieses Risiko offensichtlich ganz unabhängig von der Frage, ob es sich um ein MRGN-Isolat handelt oder nicht [13, 42, 64].

\section{Ausblick zur aktuellen Situation in deutschen NICUs}

In Deutschland wurde durch die Änderung des Infektionsschutzgesetzes 2011 (IfSG) [65] der Weg für eine zentrale Erfassung von Infektionsausbrüchen in NICUs geebnet. Allerdings muss die Compliance bei der Meldung nach $₫ 6$ Abs. 5 (3) IfSG und die Qualität der Primärdaten kontinuierlich verbessert werden. Bislang liegt die orientierend aus den NeoKISS-Daten kalkulierte Häufigkeit von Ausbrüchen in NICUs weit über der Anzahl der gemeldeten Ereignisse [66]. Für die Weiterentwicklung der Qualität von Ausbruchsberichten wäre es von erheblichem Nutzen, wenn die im ORION Statement [67] hinterlegten Grundprinzipien der Berichterstattung in Bezug auf nosokomiale Ausbrüche konsequent Beachtung fänden. Die Outbreak Database (www.outbreakdatabase.com) $[35,66,68]$ ist in diesem Kontext ein hochinformatives und praxisrelevantes Instrument.

Im Gegensatz zur Situation in anderen europäischen Ländern [69] und den USA [70] wird in Deutschland seit 2012 von der KRINKO für NICUs ein wöchentliches mikrobiologisches Kolonisationsscreening empfohlen [10, 11]. Viele Fragen in diesem Kontext sind nicht abschließend beantwortet [13]. Hierzu gehört zum Beispiel auch die Rolle des Eintrages von MRGN in die NICU durch besiedelte Eltern [71]. Der von der KRINKO bewusst eingeschlagene Weg einer proaktiven Eindämmung der nosokomialen Übertragung aufgrund von Ergebnissen des wöchentlichen Kolonisationsscreenings [12] orientiert sich am Vorsorgeprinzip der Risikoregulierung in einer besonders vulnerablen Patientenpopulation. Vor allem aufgrund des erheblichen Aufwandes wird dieser Weg nicht von allen Neonatologen und Krankenhaushygienikern befürwortet. In den aktuellen Leitlinien der Briten zur Prävention von
Infektionsausbrüchen durch gramnegative Infektionserreger in NICUs wird ein routinemäßiges mikrobiologisches Kolonisationsscreening nicht empfohlen [69]. Trotzdem führten $21 \%$ aller britischen NICUs bereits im Jahr 2012 ein solches Kolonisationsscreening durch, um die Besiedlung der Patienten mit MRGN frühzeitig zu erkennen [69]. Hier hat auf Seiten der KRINKO zwischen 2007 und 2012 eine Neuinterpretation der vorhandenen Daten zur Risikocharakterisierung unter Einbeziehung aktueller Studien stattgefunden [13]. Dies zeigt, wie wichtig es ist, die KRINKO-Empfehlungen regelmäßig an den aktuellen Stand des Wissens anzupassen, wie aufwendig dieser Prozess ist und wie schwierig solche Anpassungen vor dem Hintergrund begrenzter wissenschaftlich abgesicherter Daten in bestimmten Teilbereichen der stationären medizinischen Behandlung sein können. Die prospektive Analyse von Ausbrüchen in deutschen NICUs in den nächsten Jahren wird zeigen, ob die aktualisierten Empfehlungen der KRINKO ihre Präventionsziele erreichen und ob das Kolonisationsscreening mit angepassten Hygienemaßnahmen tatsächlich zu einer Reduktion der nosokomialen Übertragung und nachfolgend auch von nosokomialen Infektionen führt [12, 14, 72]. Hierfür ist eine sorgfältige und systematische Beschreibung der beobachteten Ereignisse (am besten im Rahmen prospektiver multizentrischer Studien innerhalb der vorhandenen Netzwerke) von großer Bedeutung.

\section{Korrespondenzadresse}

\section{Dr. M. Kraus-Haas}

Robert Koch-Institut Berlin

Nordufer 20, 13353 Berlin

Kraus-HaasM@rki.de

Danksagung. Die Autoren dieses Beitrages sind den Mitgliedern der Arbeitsgruppe neonatologische Intensivmedizin der KRINKO zu außerordentlichem Dank für Ihre ehrenamtliche Arbeit verpflichtet: Dr. Jürgen Christoph, Hannover, Prof. Dr. Christof Dame, Berlin, Dr. Tim Eckmanns, Berlin, Prof. Dr. Barbara Gärtner, Homburg, Dr. Christine Geffers, Berlin, Dr. Christian Gille, Tübingen, Priv. Doz. Dr. Christoph Härtel, Lübeck, Dr. Sebastian Haller, Berlin, Prof. Dr. Dominik Hartl, Tübingen, Dr. Matthias Marschal, Tübingen, Prof. Dr. Andreas Müller, Bonn, Priv. Doz. Dr. med. Lutz von Müller, Homburg. 


\section{Einhaltung ethischer Richtlinien}

Interessenkonflikt. M. Kraus-Haas, M. Mielke und A. Simon geben an, dass kein Interessenkonflikt besteht.

\section{Literatur}

1. Gastmeier P, Loui A, Stamm-Balderjahn S et al (2007) Outbreaks in neonatal intensive care units - they are not like others. Am J Infect Control 35:172-176

2. Adams-Chapman I (2012) Long-term impact of infection on the preterm neonate. Semin Perinatol 36:462-470

3. Gastmeier P (2014) Serratia marcescens: an outbreak experience. Front Microbiol 5:81

4. Tuffs $A$ (2011) Poor hospital hygiene is blamed for deaths of three babies in Bremen. BMJ 343:d7396

5. Tuffs A (2012) Neonatal ward in Bremen is closed down again after two more deaths of babies. BMJ 344:e1680

6. Gortner L, Borkhardt A, Reiss I (2000) Consequences of scientific reports of complications. Lancet 356:2015

7. Reiss I, Borkhardt A, Fussler R, Sziegoleit A, Gortner L (2000) Disinfectant contaminated with Klebsiella oxytoca as a source of sepsis in babies. Lancet 356:310

8. Hansen S, Stamm-Balderjahn S, Zuschneid I et al (2007) Closure of medical departments during nosocomial outbreaks: data from a systematic analysis of the literature. J Hosp Infect 65:348-353

9. Kommission für Krankenhaushygiene und Infektionsprävention beim Robert Koch-Institut (2007) Empfehlung zur Prävention nosokomialer Infektionen bei neonatologischen Intensivpflegepatienten mit einem Geburtsgewicht unter 1500 g. Bundesgesundheitsbl Gesundheitsforsch Gesundheitsschutz 50:1265-1303

10. Kommission für Krankenhaushygiene und Infektionsprävention beim Robert Koch-Institut (2012) Ergänzende Empfehlung (2012) zur "Prävention nosokomialer Infektionen bei neonatologischen Intensivpflegepatienten mit einem Geburtsgewicht unter $1.500 \mathrm{~g}^{\prime \prime}$ (2007). Epid Bull 2:13-15

11. Kommission für Krankenhaushygiene und Infektionsprävention beim Robert Koch-Institut (2013) Praktische Umsetzung sowie krankenhaushygienische und infektionspräventive Konsequenzen des mikrobiellen Kolonisationsscreenings bei intensivmedizinisch behandelten Früh- und Neugeborenen - Ergänzende Empfehlung der KRINKO beim Robert Koch-Institut, Berlin, zur Implementierung der Empfehlungen zur Prävention nosokomialer Infektionen bei neonatologischen Intensivpflegepatienten mit einem Geburtsgewicht unter 1.500 $\mathrm{g}$ aus dem Jahr 2007 und 2012. Epid Bull 42:421433

12. Simon A, Tenenbaum T (2013) Surveillance of multidrug-resistant gram-negative pathogens in highrisk neonates - Does it make a difference? Pediatr Infect Dis J 32:407-409
13. Christoph J, Dame C, Eckmanns T et al (2013) Risikocharakterisierung intensivmedizinisch behandelter Früh- und Neugeborener und Daten zur IstSituation in deutschen neonatologischen Intensivpflegestationen 2013 - Fachliche Erläuterungen zu folgender Empfehlung: Praktische Umsetzung sowie krankenhaushygienische und infektionspräventive Konsequenzen des mikrobiellen Kolonisationsscreenings bei intensivmedizinisch behandelten Früh- und Neugeborenen Ergänzende Empfehlung der Kommission für Krankenhaushygiene und Infektionsprävention (KRINKO) beim Robert Koch-Institut, Berlin zur Implementierung der Empfehlungen zur Prävention nosokomialer Infektionen bei neonatologischen Intensivpflegepatienten mit einem Geburtsgewicht unter 1.500 $\mathrm{g}$ aus dem Jahr 2007 und 2012.Epidem Bull 41 (Suppl)

14. Benenson S, Levin PD, Block C et al (2013) Continuous surveillance to reduce extended-spectrum $\beta$-lactamase Klebsiella pneumoniae colonization in the neonatal intensive care unit. Neonatology 103:155-160

15. Anderson B, Nicholas S, Sprague B, Campos J, Short B, Singh N (2008) Molecular and descriptive epidemiology of multidrug-resistant Enterobacteriaceae in hospitalized infants. Infect Control Hosp Epidemiol 29:250-255

16. Harbarth S, Sudre P, Dharan S, Cadenas M, Pittet D (1999) Outbreak of Enterobacter cloacae related to understaffing, overcrowding, and poor hygiene practices. Infect Control Hosp Epidemiol 20:598603

17. Robert Koch-Institut (2013) Bekanntmachung des Robert Koch-Institutes: Surveillance nosokomiale Infektionen sowie die Erfassung von Krankheitserregern mit speziellen Resistenzen und Multiresistenzen. Bundesgesundheitsbl Gesundheitsforsch Gesundheitsschutz 56:580-583

18. Kommission für Krankenhaushygiene und Infektionsprävention beim Robert Koch-Institut (2011) Definition der Multiresistenz gegenüber Antibiotika bei gramnegativen Stäbchen im Hinblick auf Maßnahmen zur Vermeidung der Weiterverbreitung. Epid Bull 36:337-339

19. Tamma PD, Savard P, Pal T, Sonnevend A, Perl TM, Milstone AM (2012) An outbreak of extendedspectrum $\beta$-lactamase-producing Klebsiella pneumoniae in a neonatal intensive care unit. Infect Control Hosp Epidemiol 33:631-634

20. Maltezou HC, Tryfinopoulou K, Katerelos P et al (2012) Consecutive Serratia marcescens multiclone outbreaks in a neonatal intensive care unit. Am J Infect Control 40:637-642

21. Fabbri G, Panico M, Dallolio L et al (2013) Outbreak of ampicillin/piperacillin-resistant Klebsiella pneumoniae in a neonatal intensive care unit (NICU): investigation and control measures. Int J Environ Res Public Health 10:808-815

22. Molina-Cabrillana J, Artiles-Campelo F, DortaHung E et al (2013) Outbreak of Pseudomonas aeruginosa infections in a neonatal care unit associated with feeding bottles heaters. Am J Infect Control 41:e7-e9

23. Arslan U, Erayman I, Kirdar S et al (2010) Serratia marcescens sepsis outbreak in a neonatal intensive care unit. Pediatr Int 52:208-212

24. Ligozzi M, Fontana R, Aldegheri M, Scalet G, Lo Cascio G (2010) Comparative evaluation of an automated repetitive-sequence-based PCR instrument versus pulsed-field gel electrophoresis in the setting of a Serratia marcescens nosocomial infection outbreak. J Clin Microbiol 48:1690-1695
25. Bayramoglu G, Buruk K, Dinc U, Mutlu M, Yilmaz G, Aslan Y (2011) Investigation of an outbreak of Serratia marcescens in a neonatal intensive care unit. J Microbiol Immunol Infect 44:111-115

26. MacDonald TM, Langley JM, Mailman T et al (2011) Serratia marcescens outbreak in a neonatal intensive care unit related to the exit port of an oscillator. Pediatr Crit Care Med 12:e282-286

27. Polilli E, Parruti G, Fazii P et al (2011) Rapidly controlled outbreak of Serratia marcescens infection/ colonisations in a neonatal intensive care unit, Pescara General Hospital, Pescara, Italy, April 2011. Euro Surveill 16

28. Ruiz E, Rojo-Bezares B, Saenz Y et al (2010) Outbreak caused by a multi-resistant Klebsiella pneumoniae strain of new sequence type ST341 carrying new genetic environments of aac $\left(6^{\prime}\right)-\mathrm{lb}-\mathrm{cr}$ and qnrS 1 genes in a neonatal intensive care unit in Spain. Int J Med Microbiol 300:464-469

29. Guyot K, Biran V, Doit C et al (2012) Raman spectroscopic analysis of the clonal and horizontal spread of CTX-M-15-producing Klebsiella pneumoniae in a neonatal intensive care unit. Eur J Clin Microbiol Infect Dis 31:2827-2834

30. Rettedal S, Lohr IH, Natas O, Giske CG, Sundsfjord A, Oymar K (2012) First outbreak of extendedspectrum $\beta$-lactamase-producing Klebsiella pneumoniae in a Norwegian neonatal intensive care unit; associated with contaminated breast milk and resolved by strict cohorting. Apmis 120:612621

31. McGrath EJ, Chopra T, Abdel-Haq N et al (2011) An outbreak of carbapenem-resistant Acinetobacter baumannii infection in a neonatal intensive care unit: investigation and control. Infect Control Hosp Epidemiol 32:34-41

32. Hosoglu S, Hascuhadar M, Yasar E, Uslu S, Aldudak B (2012) Control of an Acinetobacter baumannii outbreak in a neonatal ICU without suspension of service: a devastating outbreak in Diyarbakir, Turkey. Infection 40:11-18

33. Naze F, Jouen E, Randriamahazo RT et al (2010) Pseudomonas aeruginosa outbreak linked to mineral water bottles in a neonatal intensive care unit: fast typing by use of high-resolution melting analysis of a variable-number tandem-repeat locus. J Clin Microbiol 48:3146-3152

34. Yapicioglu H, Gokmen TG, Yildizdas D et al (2012) Pseudomonas aeruginosa infections due to electronic faucets in a neonatal intensive care unit. J Paediatr Child Health 48:430-434

35. Vonberg RP, Weitzel-Kage D, Behnke M, Gastmeier P (2010) Worldwide Outbreak Database: the largest collection of nosocomial outbreaks. Infection 39:29-34

36. Bührer C, Genzel-Boroviczeny O, Jochum F et al (2014) Warnung vor Verwendung unzureichend geprüfter Muttermilch - Stellungnahme der Deutschen Gesellschaft für Kinder- und Jugendmedizin. Monatsschr Kinderheilkd 162:722

37. Vonberg RP, Gastmeier P (2007) Hospital-acquired infections related to contaminated substances. $J$ Hosp Infect 65:15-23

38. Exner M, Kramer A, Lajoie L, Gebel J, Engelhart S, Hartemann P (2005) Prevention and control of health care-associated waterborne infections in health care facilities. Am J Infect Control 33:26-40

39. Exner M, Kramer A, Kistemann T, Gebel J, Engelhart $S$ (2007) Water as a reservoir for nosocomial infections in health care facilities, prevention and control. Bundesgesundheitsbl Gesundheitsforsch Gesundheitsschutz 50:302-311 
40. Walker JT, Jhutty A, Parks S et al (2014) Investigation of healthcare-acquired infections associated with Pseudomonas aeruginosa biofilms in taps in neonatal units in Northern Ireland. J Hosp Infect 86:16-23

41. Halabi M, Wiesholzer-Pittl M, Schoberl J, Mittermayer $\mathrm{H}$ (2001) Non-touch fittings in hospitals: a possible source of Pseudomonas aeruginosa and Legionella spp. J Hosp Infect 49:117-121

42. Voelz A, Muller A, Gillen J et al (2010) Outbreaks of Serratia marcescens in neonatal and pediatric intensive care units: clinical aspects, risk factors and management. Int J Hyg Environ Health 213:79-87

43. Sweeney AM, Lyle J, Ferguson ND (2005) Nursing and infection-control issues during high-frequency oscillatory ventilation. Crit Care Med 33:204208

44. Haertel C, Simon A, Geffers C et al (2013) Nosokomiale Infektionen bei Frühgeborenen - Umsetzung der KRINKO-Empfehlungen im Deutschen Frühgeborenennetzwerk. Monatsschr Kinderheilkd 161:27-33

45. Landelle C, Pagani L, Harbarth S (2013) Is patient isolation the single most important measure to prevent the spread of multidrug-resistant pathogens? Virulence 4:163-171

46. Rogowski JA, Staiger D, Patrick T, Horbar J, Kenny M, Lake ET (2013) Nurse Staffing and NICU Infection Rates. JAMA Pediatr 167:444-450

47. Bauer K, Vetter K, Groneck P et al (2006) Empfehlungen für die strukturellen Voraussetzungen der perinatologischen Versorgung in Deutschland. Z Geburtshilfe Neonatol 210:19-24

48. Gesellschaft für Neonatologie und Pädiatrische Intensivmedizin (2004) Empfehlungen der GNPI für strukturelle Voraussetzungen der neonatologischen Versorgung von Früh- und Neugeborenen in Deutschland. 24.06.2004. http://www.gnpi.de/. Zugegriffen: 29. Jan 2015

49. Hawkins G, Stewart S, Blatchford O, Reilly J (2011) Should healthcare workers be screened routinely for meticillin-resistant Staphylococcus aureus? A review of the evidence. J Hosp Infect 77:285-289

50. Kommission für Krankenhaushygiene und Infektionsprävention beim Robert Koch-Institut (2002) Ausbruchmanagement und strukturiertes Vorgehen bei gehäuftem Auftreten nosokomialer Infektionen. Empfehlung der Kommission für Krankenhaushygiene und Infektionsprävention beim Robert Koch-Institut. Bundesgesundheitsbl Gesundheitsforsch Gesundheitsschutz 45:180-186

51. Exner M (2012) [Experiences with outbreaks of nosocomial infections]. Bundesgesundheitsbl Gesundheitsforsch Gesundheitsschutz 55:1432-1443

52. Kramer A, Schwebke I, Kampf G (2006) How long do nosocomial pathogens persist on inanimate surfaces? A systematic review. BMC Infect Dis 6:130

53. Oteo J, Cercenado E, Vindel A et al (2013) Outbreak of a multidrug-resistant CTX-M-15-producing Enterobacter cloacae in a neonatal intensive care unit. J Med Microbiol 62:571-575

54. Oteo J, Perez-Vazquez M, Campos J (2010) Extended-spectrum [beta]-lactamase producing Escherichia coli: changing epidemiology and clinical impact. Curr Opin Infect Dis 23:320-326

55. Strenger V, Gschliesser T, Grisold A et al (2011) Orally administered colistin leads to colistin-resistant intestinal flora and fails to prevent faecal colonisation with extended-spectrum $\beta$-lactamase-producing enterobacteria in hospitalised newborns. Int J Antimicrob Agents 37:67-69
56. Oren I, Sprecher H, Finkelstein R et al (2013) Eradication of carbapenem-resistant Enterobacteriaceae gastrointestinal colonization with nonabsorbable oral antibiotic treatment: a prospective controlled trial. Am J Infect Control 41:1167-1172

57. Tamma PD, Lee CK (2009) Use of colistin in children. Pediatr Infect Dis J 28:534-535

58. Strenger V, Feierl G, Resch B et al (2013) Fecal carriage and intrafamilial spread of extended-spectrum $\beta$-lactamase-producing Enterobacteriaceae following colonization at the neonatal ICU. Pediatr Crit Care Med 14:157-163

59. Lohr IH, Rettedal S, Natas OB, Naseer U, Oymar K, Sundsfjord A (2013) Long-term faecal carriage in infants and intra-household transmission of CTXM-15-producing Klebsiella pneumoniae following a nosocomial outbreak. J Antimicrob Chemother 68:1043-1048

60. Lee J, Pai H, Kim YK et al (2007) Control of extended-spectrum $\beta$-lactamase-producing Escherichia coli and Klebsiella pneumoniae in a children's hospital by changing antimicrobial agent usage policy. J Antimicrob Chemother 60:629-637

61. Le J, Nguyen T, Okamoto M, McKamy S, Lieberman JM (2008) Impact of empiric antibiotic use on development of infections caused by extended-spectrum $\beta$-lactamase bacteria in a neonatal intensive care unit. Pediatr Infect Dis J 27:314-318

62. Tsai MH, Chu SM, Hsu JF et al (2014) Risk factors and outcomes for multidrug-resistant Gram-negative bacteremia in the NICU. Pediatrics 133:e322329

63. Patel SJ, Saiman L (2012) Principles and strategies of antimicrobial stewardship in the neonatal intensive care unit. Semin Perinatol 36:431-436

64. Berger A, Rohrmeister K, Haiden N, Assadian O, Kretzer V, Kohlhauser C (2002) Serratia marcescens in the neonatal intensive care unit: re-emphasis of the potentially devastating sequelae. Wien Klin Wochenschr 114:1017-1022

65. Gesetz zur Verhütung und Bekämpfung von Infektionskrankheiten beim Menschen (Infektionsschutzgesetz - IfSG) (2000) Zuletzt geändert durch Art. 1 G v. 28.7.2011. http://www.gesetze-im-internet.de/bundesrecht/ifsg/gesamt.pdf. Zugegriffen: 29. Jan 2015

66. Schwab F, Geffers C, Piening B, Haller S, Eckmanns T, Gastmeier P (2014) How many outbreaks of nosocomial infections occur in German neonatal intensive care units annually? Infection 42:73-78

67. Stone SP, Cooper BS, Kibbler CC et al (2007) The ORION statement: guidelines for transparent reporting of outbreak reports and intervention studies of nosocomial infection. J Antimicrob Chemother 59:833-840

68. Danzmann L, Gastmeier P, Schwab F, Vonberg RP (2013) Health care workers causing large nosocomial outbreaks: a systematic review. BMC Infect Dis 13:98

69. Anthony M, Bedford-Russell A, Cooper T et al (2013) Managing and preventing outbreaks of Gram-negative infections in UK neonatal units. Arch Dis Child Fetal Neonatal Ed 98:F549-F553

70. Harris AD, McGregor JC, Furuno JP (2006) What infection control interventions should be undertaken to control multidrug-resistant gram-negative bacteria? Clin Infect Dis 43(Suppl 2):57-61

71. Laux R, Wirtz S, Huggett S, Ilchmann C (2013) Relevance of parents as source for contamination of neonates with multiresistant Gram-negative pathogens (MRGN). Z Geburtshilfe Neonatol 217:6164
72. Murillo JL, Cohen M, Kreiswirth B (2010) Results of nasal screening for methicillin-resistant Staphylococcus aureus during a neonatal intensive care unit outbreak. Am J Perinatol 27:79-81 